Canadian

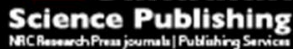

Canadian Geotechnical Journal Revue canadienne de géotechnique

\title{
Experimental study on dynamic interference effect of two closely spaced machine foundations
}

\begin{tabular}{|r|l|}
\hline Journal: & Canadian Geotechnical Journal \\
\hline Manuscript ID: & cgj-2014-0462.R1 \\
\hline Manuscript Type: & Article \\
\hline Date Submitted by the Author: & 25-Apr-2015 \\
\hline Complete List of Authors: & $\begin{array}{l}\text { Swain, Abhijeet; IIT Kanpur, } \\
\text { Ghosh, Priyanka; Indian Institute of Technology, Kanpur }\end{array}$ \\
\hline Keyword: & $\begin{array}{l}\text { Dynamic interference, Machine foundation, Model test, Square foundation, } \\
\text { Vibration }\end{array}$ \\
\hline \multicolumn{2}{|l}{} \\
\hline
\end{tabular}

\section{SCHOLARONE \\ Manuscripts}




\title{
Experimental study on dynamic interference effect of two closely spaced machine foundations
}

\author{
Abhijeet Swain ${ }^{\mathrm{a}}$ and Priyanka Ghosh ${ }^{\mathrm{b}, *}$ \\ ${ }^{\mathrm{a}}$ Research Scholar, \\ Department of Civil Engineering, Indian Institute of Technology, Kanpur, \\ Kanpur - 208 016, India \\ ${ }^{\mathrm{b}}$ Associate Professor, \\ Department of Civil Engineering, Indian Institute of Technology, Kanpur, \\ Kanpur - 208 016, India
}

Corresponding author: Dr. Priyanka Ghosh

(E-mail address: priyog@iitk.ac.in, Tel: +91-512-2597022, Fax: +91-512-2597395)

\begin{abstract}
This paper presents an experimental study on the dynamic interaction effect of closely spaced square foundations under machine vibration. Under dynamic condition, a number of large-scale model tests were conducted in the field, which include a wide range of study on the isolated as well as the interacting footing response resting on the local soil available at Kanpur, India. The dynamic interaction of different combinations (size) of two-footing assembly was investigated by inducing vertical harmonic load on one of the footings (active footing), where the other footing (passive footing) was loaded with the static weight only. The active footing was excited with different


magnitudes of dynamic loading and the response was recorded for both the footings, placed at different clear spacing (S). The results are compiled and shown as the variation of displacement amplitude with frequency. The transmission ratio, which predicts the effect of dynamic excitation of the active footing on the passive one, is determined for the interacting footings and plotted with respect to the frequency ratio.

Keywords: Dynamic interference; Machine foundation; Model test; Square foundation;

\section{Vibration}




\section{Introduction}

Harmonic and periodic vibrations can be generated mostly by heavy machines, moving vehicles or by running trains, which cause the supporting foundations to behave in a different fashion. Therefore, these foundations should be designed properly to resist such dynamic loads to have a greater serviceability and longevity. Expertise has been developed starting from the simple spring-mass-dashpot system to the rigorous elastic half space model proposed by Sung (1953), Lysmer and Richart (1966), Richart et al. (1970), Gazetas (1991) and Kameswar Rao (1998, 2011) for single isolated foundation. However, when the foundations are located in groups, the interference of one on the other neighboring foundations due to such dynamic loading is likely to occur significantly. Hence, the importance of such study cannot be ignored in the design of closely spaced foundations experiencing dynamic interaction.

The problem of soil-structure interaction has been the most active area of research in the field of geotechnical engineering. Several studies have been performed to understand the soil-structure interaction under dynamic loading. The studies conducted by Liang (1974), Lysmer et al. (1975), Wong and Luco (1986), Tham et al. (1998), Ghosh (2011), Ghosh and Kumari (2012), and Ghosh (2013) explain the interference effect of nearby foundations and ground anchors under the earthquake loading using different numerical techniques such as finite element, finite difference and boundary element method. However, very few studies (Vivek and Ghosh 2012, Ghosh 2013) have been performed on the interference effect of foundations subjected to machine vibration. Machine foundations are basically designed for mounting of heavy machines generating unwanted unbalanced periodic forces. The available methodology is good enough to design single isolated machine foundation. However, in several practical situations, the machine foundations may be found in a group and placed closely, due to 
space crunch or some inevitable conditions. The behavior of closely spaced machine foundations is expected to be significantly different than that of single isolated machine foundation due to their interaction within the group. Hence, the dynamic interaction amongst these closely spaced machine foundations may be of great interest of research to obtain their safe design methodology.

Several analytical and numerical studies (Warburton et al. 1971; Wong and Luco 1986; Triantafyilidis and Prange 1989; Wang et al. 1991; Wang and Schmid 1992; Qian and Beskos 1996; Karabalis and Mohammadi 1991, 1998) have been conducted to understand the dynamic interaction of foundations in a group. However, lack of experimental study on the interference behavior of nearby machine foundations motivates to take up the present investigation, which explains the dynamic interaction effect between two closely spaced square foundations of two different sizes, by conducting large scale model experiments. The interaction effect of two-footing assembly was obtained by mounting a Lazan type mechanical oscillator and motor assembly on the active footing, which produces purely vertical vibrations on the footing. On the contrary, the passive footing was placed adjacent to the active one and loaded with the dead weights, which produces same static load intensity as that exerted by the active footing. Accelerometer was used to measure the acceleration, velocity and displacement amplitude of the steady state vibration, both for active and passive footings. The tests were performed with the active and passive footings kept at different spacing and at a certain depth $\left(\mathrm{D}_{\mathrm{f}}=0.55 \mathrm{~B}\right.$ and $0.45 \mathrm{~B}$ for $550 \mathrm{~mm}$ and $650 \mathrm{~mm}$ wide footings respectively, where B is the width of the footing) below the ground surface. 


\section{Experimental details}

The experimental program majorly includes the study on the dynamic response of isolated footings and the dynamic interaction of two-footing assembly. The basic arrangement includes the block vibration test setup and other accessories.

\section{Test setup and material}

The present experimental setup was designed based on the IS code provisions (IS-5249) and on the programs presented by various researchers (Erden 1974; Baidya 1992; Baidya and Muralikrishna 2001; Baidya and Mandal 2006; Baidya and Rathi 2004; Kumar and Reddy 2006; Mandal et al. 2012) on the analysis of foundations subjected to harmonic vibrations (or block vibration tests). A general layout of the present test setup for the block vibration test and the dynamic interaction of footings is shown in Fig. 1. RCC square footings made of M20 grade concrete were casted to serve as the model footings, in two different sizes: (a) Footing 1 (F1): $0.55 \mathrm{~m} \times 0.55 \mathrm{~m} \times 0.2 \mathrm{~m}-2$ numbers, (b) Footing 2 (F2): $0.65 \mathrm{~m} \times 0.65 \mathrm{~m} \times 0.2 \mathrm{~m}-2$ numbers. A provision for mounting the vibrating machine over the footing was made, by incorporating foundation bolts (20 $\mathrm{mm}$ in diameter) at four corners of the footing. Mild steel (MS) plates and discs were used to achieve any desired level of static load intensity below the active and the passive footings. Square shaped mild steel plates of size $0.45 \mathrm{~m} \times 0.45 \mathrm{~m} \times 0.016 \mathrm{~m}$ were employed with $25 \mathrm{~mm}$ diameter clear holes at the four corners to fit on the foundation bolts. Along with that, circular slotted weights $(16 \mathrm{~kg}$ and $20 \mathrm{~kg}$ in mass) of $30 \mathrm{~cm}$ in diameter were used for loading the passive footing statically, which can be seen in Fig. 1. A Lazan rotating mass type mechanical oscillator, developed by the New Engineering Enterprises, India, was clamped over the MS base plate to generate a sinusoidal varying dynamic force. The force generated by 
the oscillator depends on the angular velocity of rotation and the angle of eccentricity between the eccentric unbalanced masses present inside the oscillator. The force generated can be calculated using the following relation

$$
F_{0}=m_{e} \cdot e \cdot \omega^{2}=0.119 \omega^{2} \sin \left(\frac{\theta}{2}\right)
$$

where, $\mathrm{F}_{0}$ is the force in $\mathrm{N}, \mathrm{m}_{\mathrm{e}}$ is the eccentric unbalanced mass rotating with a radius of e, $\omega$ is the angular frequency in $\mathrm{rad} / \mathrm{sec}$ and $\theta$ is the angle between the eccentric masses. A variable speed 3HP DC motor was used to operate the mechanical oscillator to run at different frequency ranging from $120 \mathrm{rpm}-3000 \mathrm{rpm}$. The DC motor was placed and clamped over the oscillator and their shafts were connected with a V-belt as shown in Fig. 1. A speed controller unit was placed outside the pit (Fig. 1a) for controlling the speed of the DC motor. A low ' $\mathrm{g}$ ' high output MEMS accelerometer, manufactured by Micron, India was employed to measure the acceleration response of the footings. The output from the accelerometer was displayed on a digital vibration meter in terms of the peak amplitudes of the acceleration, velocity and displacement due to the vibration. All the tests were conducted in pits of depth $300 \mathrm{~mm}$ to avoid the top loose soil, which were properly leveled before placing the footings over it. A photographic view of the experimental setup employed for studying the dynamic interaction of footings is shown in Fig. 2. All the experiments were performed in the geotechnical in-situ laboratory site of IIT-Kanpur campus, Kanpur, Uttar Pradesh, India, where the soil strata comprises mostly of silt with some clay and very less sand content (Chanda 2011). The top $2 \mathrm{~m}$ depth of the layer was found to be clayey-silt with some kankar. The liquid limit was found to be as low as about $35 \%$. The plasticity index was also found to be in low to medium range and the natural moisture content up to $2.0 \mathrm{~m}$ depth was observed as approximately $17 \%$, during the testing period. The water table 
was generally found to be located below $6.5 \mathrm{~m}$, which was reasonably beyond the zone of influence.

\section{Testing procedure}

Initially, the dynamic response of two different isolated footings (F1 and F2) was recorded. The complete assembly for the block vibration test was prepared (Fig. 1) and placed in a pit of dimension $1.4 \mathrm{~m} \times 1.4 \mathrm{~m} \times 0.3 \mathrm{~m}$, found to be sufficient for easy placement of the footing and machine assembly. The load intensity below the footings (F1 and F2) was maintained as $10,750 \mathrm{~N} / \mathrm{m}^{2}$, which was found to be well within the working load and was the optimum value that could be achieved using the available experimental resources. The force $\left(\mathrm{F}_{0}\right)$ of vibration was set in the oscillator by keeping the eccentric angle setting $(\theta)$ of the oscillator to a desired value. All tests were performed at three different magnitudes of $\theta\left(16^{\circ}, 24^{\circ}\right.$ and $\left.32^{\circ}\right)$, and the corresponding values of eccentric force $\left(\mathrm{m}_{\mathrm{e}} \cdot \mathrm{e}\right)$ were obtained as $0.017 \mathrm{~N}-\mathrm{sec}^{2}, 0.025 \mathrm{~N}-\mathrm{sec}^{2}$ and 0.033 $\mathrm{N}-\sec ^{2}$, respectively. The eccentric force setting was limited to the aforementioned values, to avoid the vibration causing any separation between the footing and the soil. The response was measured using the accelerometer as mentioned earlier. The accelerometer was placed along the centre line on the front edge of the footings as shown in Fig. 2 and enough care was taken to record only the vertical vibration. The footing responses were noted for the frequency increments in the range of 50rpm to 100rpm approximately, so as to obtain an accurate trend in the results. At each frequency, the response parameters were noted after 5 to 10 secs from the initiation of foundation excitation to ensure a steady state vibration condition and thus, the instantaneous recording of readings was discouraged. Few selected combinations of model footing assembly, consisting of same or different size of footings, were 
considered to study the dynamic interaction effect between two closely placed footings. Both active and passive footings were loaded to have a static load intensity of 10,750 $\mathrm{N} / \mathrm{m}^{2}$ on each footing. A pit of suitable dimension was prepared to accommodate the whole setup as shown in Fig. 3. The tests were conducted at four different S/B ratios $(0.45,0.90,1.35$ and 1.80$)$. At each $\mathrm{S} / \mathrm{B}$ ratio, the dynamic response of active and passive footings was recorded for three different eccentric force settings as mentioned earlier.

\section{Experimental program}

Total 45 numbers of tests were performed and the sequence of all experiments performed in the present study is shown in Table 1. Some selective tests were conducted more than once to ensure the repeatability of the tests. The tests on isolated footings (F1 and F2) were conducted first in two different pits (P1 and P2), which were later extended to perform the tests on different pair of interactive active and passive footings. Each test is identified by a specific nomenclature assigned to it as $\mathrm{I}_{\mathrm{ij}} \mathrm{S}_{\mathrm{m}} \mathrm{E}_{\mathrm{n}}$. $\mathrm{I}_{\mathrm{ij}}$ represents the dynamic interaction of active $\left(F_{i}\right)$ and passive $\left(F_{j}\right)$ footings, where $i=\{1$, $2\}$ and $\mathrm{j}=\{0,1,2\}, \mathrm{j}=0$ represents the special case of isolated $\left(\mathrm{F}_{\mathrm{i}}\right)$ footing of different sizes. $\mathrm{S}_{\mathrm{m}}$ represents the spacing between the footings, where $\mathrm{m}$ stands for different $\mathrm{S} / \mathrm{B}$ values $(0.0,0.45,0.90,1.35$ and 1.80). It is worth noting here that the special case of isolated footing can be represented by $S / B=0$ along with $j=0 . E_{n}$ represents different eccentric angle setting for the vibrating force and $n=\{16,24,32\}$ stands for different magnitude of $\theta$ in degrees. 


\section{Results and discussions}

After attaining the steady state vibration in each test, the variation of displacement amplitude of the footing was recorded with respect to the frequency of vibration of the oscillator. In the subsequent sections, the results are presented and discussed in nondimensional form to reflect the generality.

\section{Isolated footing}

The block vibration test was conducted for the footings F1 and F2 and the response was recorded for three different eccentric force settings. For footings F1 and F2, the variation of the displacement amplitude with the frequency is plotted in Fig. 4 for different eccentric settings. It can be observed that with increase in the value of eccentric force $\left(m_{e} . e\right)$, the resonant frequency decreases but the resonant displacement amplitude increases. From the steady state vibration theory for the rotating mass type vibration, the following equations can be derived (Richart et al. 1970) to compute the magnitudes of equivalent stiffness $(k)$ and damping ratio (D):

$$
\begin{aligned}
& \frac{z_{r}}{\left(\frac{m_{e} \cdot e}{m}\right)}=\frac{1}{2 D \sqrt{1-D^{2}}} \\
& f_{m r}=\frac{1}{2 \pi \sqrt{1-2 D^{2}}} \sqrt{\frac{k}{m}}
\end{aligned}
$$

where, $z_{r}$ is the vertical displacement of vibration at resonance, $m_{e}$ is the eccentric unbalanced mass in the rotating mass type system, e is the radius of rotation of the eccentric mass, $\mathrm{m}$ is the total mass of the vibrating system and $\mathrm{f}_{\mathrm{mr}}$ is the resonant frequency for the rotating mass type system. The dynamic properties of the soil 
evaluated are reported in Table 2. It can be noted that the magnitude of the natural frequency and the stiffness of the soil generally decreases with increase in the value of $\theta$. In Fig. 5, the variation of the magnification factor with the frequency ratio is plotted in non-dimensional form, where the frequency ratio and magnification factor can be expressed as:

$$
\begin{aligned}
& \text { Frequency ratio }\left(f_{r}\right)=\frac{f}{f_{n}} \\
& f_{n}=\frac{1}{2 \pi} \sqrt{\frac{k}{m}} \\
& \text { Magnification factor }(M)=\frac{\mathrm{z}}{\left(\frac{m_{e} \cdot e}{m}\right)}
\end{aligned}
$$

where, $\mathrm{z}$ is the vertical displacement amplitude of vibration, $\mathrm{f}$ is the operating frequency and $f_{n}$ is the natural frequency of the soil considering the mass of the active vibrating system. It can be observed from Fig. 5 that the magnification factor, $M$ attains a peak beyond $f_{r}=1$, which is in line with the response generally obtained for rotating mass type excitation (Richart et al. 1970; Kameswar Rao 2011). For both the footings, no significant variation in the magnification factor can be noticed up to $f_{r}=1$ for different eccentric force settings. For the footings F1 and F2, the peak magnitude of M varies approximately from 2.6 to 2.7 and from 3.1 to 3.6 with increase in the eccentric force setting from $0.017 \mathrm{~N}-\sec ^{2}$ to $0.033 \mathrm{~N}-\sec ^{2}$ respectively. The magnitude of total damping (material damping + radiation damping) ratio for the footing F1 was found to be approximately $18.3 \%$ for all the eccentric force values (Table 2). Similarly for the footing F2, the damping ratio was observed to vary approximately from $13.8 \%$ to $16.2 \%$ with increasing eccentric settings (Table 2). 
The present results obtained for the isolated footing are qualitatively compared with those reported by previous researchers since the studies were conducted in different experimental environments. In Fig. 6, the present variation of soil stiffness $(\mathrm{k})$ and damping ratio (D) with the eccentric force setting is compared with that predicted by Kumar and Reddy (2006). The soil type, footing dimensions and vibrating weight were different in the present study as compared to those considered in the study of Kumar and Reddy (2006). However, the type of loading (rotating mass type excitation) was same in both the investigations. A good agreement in the trends can be observed. The soil stiffness is found to decrease whereas the damping ratio is seen to increase with the increase in the eccentric force setting for both the cases. It is worth mentioning that the similar trend was also observed by several other researchers (Baidya 1992; Baidya and Muralikrishna 2001; Baidya and Mandal 2006; Baidya and Rathi 2004; Kumar and Reddy 2006). Bhoumik (1989) conducted block vibration test on a large concrete block in the Geotechnical Engineering Laboratory site of IIT Kanpur campus. In Table 3, the test details and results obtained from the present study are compared with the results reported by Bhoumik (1989) and a good agreement can be observed in the values of natural frequency and damping of the soil.

\section{Interacting footings}

Several tests were conducted on the interfering footings F1 and F2 in four basic combinations (F1-F1, F1-F2, F2-F1 and F2-F2) to explore the dynamic interaction between two nearby footings. The variation of the displacement amplitude with the frequency for both active and passive footings is presented in Figs. 7-10. No significant variation can be observed in the response of the active footing when compared with that of the isolated footing response at the same eccentric setting. It is worth noting that the 
feedback from the passive footing might have some measurable effect on the response of the active footing, which in the present case was found to have negligible effect on the vertical response and hence this factor was neglected. The active footing response also remains almost unchanged at different $\mathrm{S} / \mathrm{B}$ ratios, for the eccentric setting being constant. However, at a particular eccentric force setting, the response of the passive footing shows significant variation in the displacement amplitude with the frequency at different $\mathrm{S} / \mathrm{B}$ ratios. The present observations are reported for the machines operating within its working range of frequency $(120 \mathrm{rpm}-3000 \mathrm{rpm})$. The magnitude of the peak displacement of the passive footing is found to be lower than that of the active footing at every S/B ratio. The resonant frequency for the passive footing is found to be higher than that of the active footing and this difference in the frequencies may be attributed to the phase lag between the response of the active and the passive footings. The phase lag is found to increase with the increase in S/B ratio, whereas the reverse trend can be observed for the resonant displacement amplitude of the passive footing. For the passive footing, the phase lag attributes to a sudden rise in the rate of increase in $z(t)$ by attaining a local peak near the resonant condition of the active footing followed by nearly constant variation in $z(t)$, which further increases at a higher rate to attain the peak value near the resonance of the passive footing. However, after resonance, $z(t)$ decreases and eventually attains almost constant value. This phase lag concept can be clearly observed from the response of the passive footing as shown in Figs. 7-10. A well-defined resonance can be observed for the passive footing at $\mathrm{S} / \mathrm{B}=0.45$. However, the phase lag increases at $\mathrm{S} / \mathrm{B}>0.45$ and the point of resonance shifts forward and in some cases, it shifts beyond the upper limit of the operating frequency range. This might have resulted in non-availability of well defined resonant peaks at higher S/B ratios. At any spacing and eccentric setting, the magnitude of the resonant displacement 
amplitude for the passive footing is found to be higher for $\mathrm{I}_{11} \mathrm{~S}_{\mathrm{m}} \mathrm{E}_{\mathrm{n}}$ as compared to $\mathrm{I}_{12} \mathrm{~S}_{\mathrm{m}} \mathrm{E}_{\mathrm{n}}$. This indicates that the increase in the size of the passive footing decreases the magnitude of the resonant displacement amplitude for the passive footing by keeping the same active footing. The magnitude of the resonant displacement amplitude for the passive footing is found to be higher for the tests $I_{11} S_{m} E_{n}$ and $I_{12} S_{m} E_{n}$ as compared to that obtained from the tests $\mathrm{I}_{21} \mathrm{~S}_{\mathrm{m}} \mathrm{E}_{\mathrm{n}}$ and $\mathrm{I}_{22} \mathrm{~S}_{\mathrm{m}} \mathrm{E}_{\mathrm{n}}$, respectively. This shows that the increase in size of the active footing reduces the magnitude of the resonant displacement amplitude for the passive footing keeping all other parameters same. Fig. 11 presents the dynamic response of passive footing in different combinations for different values of $\theta$ at $\mathrm{S} / \mathrm{B}=0.45$. It can be noted that the magnitude of displacement amplitude, $\mathrm{z}(\mathrm{t})$ of the passive footing increases with increase in the exciting force on the active footing at a particular S/B ratio. The resonance frequency of the passive footing is found to decrease with increase in the magnitude of eccentric force setting $\left(\mathrm{m}_{\mathrm{e}} \cdot \mathrm{e}\right)$. Similar trend is also observed in the passive footing response for other values $\mathrm{S} / \mathrm{B}$ ratio.

The effect of dynamic interaction between the footings can be expressed in terms of transmission ratio $\left(\mathrm{T}_{\mathrm{r}}\right)$, which is defined as:

$$
\mathrm{T}_{\mathrm{r}}=\frac{\text { Vertical translational displacement amplitude of passive footing }}{\text { Vertical translational displacement amplitude of active footing }}
$$

In Figs. 12-15, the transmission ratio is plotted with respect to the normalized frequency ratio $\left(f_{r}\right)$. The frequency is normalized with respect to the natural frequency of the active footing-soil system as defined in Eq. 4. It can be noticed that the variation of $T_{r}$ generally decreases initially to reach a local minimum and then increases gradually to reach the peak corresponding to the maximum $\mathrm{T}_{\mathrm{r}}$. Generally, the local minima in the variation of $T_{r}$ can be observed close to $f_{r}=1$ representing the natural 
frequency of the soil with respect to the active vibrating system, whereas the transmission ratio can be seen to attain the maximum value at the resonant point of the passive footing. The resonance in the active footing is observed to occur at a frequency ratio $\left(f_{r}^{m}=f_{m r} / f_{n}\right) \approx 1.025$. The difference between $f_{r}^{m}$ and $f_{r}$ corresponding to maximum $\mathrm{T}_{\mathrm{r}}$ may be attributed due to the phase lag, as discussed earlier. Similar observations are also valid for other set of test cases. The phenomena of achieving local minimum and maximum in the variation of $\mathrm{T}_{\mathrm{r}}$ can be explained subsequently. When the operating frequency approaches the natural frequency of the soil, the rate of increase in the response parameter (displacement, velocity or acceleration) of the active footing shoots up rapidly, whereas the rate of increase in the corresponding response parameter in the passive footing is found to be significantly less. Hence, the magnitude of $T_{r}$ is observed to decrease initially. At a particular operating frequency, the rate of increase in the response parameters becomes almost same for both active and passive footings, which can be denoted by the local minimum point. Just after the resonant condition of the active footing, the response parameters of the active footing start decreasing, whereas the passive footing continues to receive increasingly higher energy from the active footing through the soil due to the increase in the frequency of vibration on the active footing. This probably results in an increasing rate of the response parameters of the passive footing, which causes the transmission ratio to increase gradually. At some frequency beyond the local minimum point, the passive footing experiences the resonance. The transmission ratio mostly attains the maximum value corresponding to the resonant frequency of the passive footing. However, the predominance of the local minima gets diminishing gradually with increase in the S/B ratio due to lower energy received by the passive footing causing reduction in the interaction with increasing spacing. Further, the response parameters for both active and passive footings decrease 
with increase in the frequency, which results in decrease in $T_{r}$ value beyond the peak. Table 4 shows the variation of the maximum value of $T_{r}$ with $S / B$ ratio and eccentric setting $(\theta)$. The values of maximum $T_{r}$ are generally found to decrease with increase in the eccentric setting $(\theta)$ for a given combination of footings and at a particular spacing. This may be due to the rate of increase in the vibration energy received by the passive footing is less than that induced on the active footing. It can be noted that the magnitude of maximum $T_{\mathrm{r}}$ decreases rapidly with increase in the spacing between the footings, which indicates that the interaction of closely spaced footings decreases with increase in the spacing. It is worth mentioning here that the criteria for terminating any experiment at a particular $\mathrm{S} / \mathrm{B}$ ratio was based on the maximum Transmission ratio $\left(\mathrm{T}_{\mathrm{r}}\right)$ falling below $7.5 \%$, which actually represents negligible interaction between the footings i.e., if for a particular $\mathrm{S} / \mathrm{B}$ ratio, the maximum $\mathrm{T}_{\mathrm{r}} \leq 7.5 \%$, then the experiment was stopped, else the test was performed for the next higher S/B ratio. The terminating criteria being maximum $\mathrm{T}_{\mathrm{r}} \leq 7.5 \%$ was chosen to be an approximate value by performing trial tests, which resulted in negligible variation to be recorded in the passive footing and no well-defined response curve was obtained..

\section{Summary and conclusions}

Present advanced stage of industrialization often includes heavy machines operating at high frequencies, which may affect the nearby foundations or structures and its own operation may be hampered due to working of other machines in close proximity to it. Therefore, the present investigation aimed to study the interference effect of closely spaced machine foundations, which should be taken into consideration during the design of machine foundations and their installation. Large scaled model tests were conducted using model RCC footings (square in shape) to study the dynamic response 
of isolated and two closely spaced interacting foundations. All tests were conducted in the geotechnical in-situ laboratory of IIT Kanpur, India. The variation of the displacement amplitude with the frequency was studied for two different sizes of footings (F1 and F2). The dynamic properties of the soil at the test site were obtained from the block vibration test conducted on the isolated footing and were validated with the available data. The dynamic interaction of two footings in combination was investigated by maintaining the same magnitude of static load intensity of $10,750 \mathrm{~N} / \mathrm{m}^{2}$ below each footing. The response of the active and passive footings was recorded and studied for exploring the dynamic interaction of footings F1 and F2 in four different combinations. The tests were conducted for different $\mathrm{S} / \mathrm{B}$ ratios $(0.45,0.90,1.35$ and $1.80)$ and at different vibrating force (eccentric) settings $\left(\theta=16^{\circ}, 24^{\circ}\right.$ and $\left.32^{\circ}\right)$. The dynamic interaction of the active and passive footings was observed by studying the variation of transmission ratio $\left(\mathrm{T}_{r}\right)$ with the frequency ratio $\left(\mathrm{f}_{\mathrm{r}}\right)$. It can be observed that the passive footing undergoes resonance due to the dynamic excitation on the active footing, which occurs, however, with a phase lag from the resonant frequency of the active footing. This phase lag is found to be a vital parameter in defining the dynamic interaction of a group of footings. The phase lag is observed to decrease with decrease in the spacing between the footings. The variation of transmission ratio is generally associated with a minimum and a maximum point. The minimum point occurs as $T_{r}$ approaches the resonance of the active footing $\left(f_{r}=1\right)$, whereas the maximum occurs at the frequency ratio associated with resonance of the passive footing. 


\section{References}

Baidya, D.K. 1992. Dynamic response of foundations resting on layered and nonhomogeneous soils. Ph.D. Thesis, Indian Institute of Science, Bangalore, India.

Baidya, D.K., and Muralikrishna, G. 2001. Investigation of resonant frequency and amplitude of vibrating footing resting on a layered soil system. Geotechnical Testing Journal, 24(4): 409-417.

Baidya, D.K., and Mandal, A. 2006. Dynamic response of footing resting on a layered soil system. West Indian Journal of Engineering, 28(2): 65-79.

Baidya, D.K., and Rathi, A. 2004. Dynamic response of footings resting on a sand layer of finite thickness. Journal of Geotechnical and Geoenvironmental Engineering, ASCE, 130(6): 651-655.

Bhoumik, K. 1989. Coupled vibration of footings on elastic half-space. M.Tech Thesis, I.I.T-Kanpur, Kanpur, India.

Chanda, S. 2011. Measurement of shear wave velocity and evaluation of liquefaction potential of kanpur soil by seismic downhole technique. M.Tech. Thesis, I.I.TKanpur, Kanpur, India.

Erden, S.M. 1974. Influence of shape and embedment on dynamic foundation response.

Ph.D. Thesis, University of Massachusetts, Amherst.

Gazetas, G. 1991. Formulas and charts for impedances of surface and embedded foundations. Journal of Geotechnical Engineering, ASCE. 117(9): 1363-1381.

Ghosh, P. 2011. Seismic interference effect of two nearby square footings. Geotechnical Special Publication, ASCE (GSP 211): 352-361. 
Ghosh, P. 2012. FLAC based numerical studies on dynamic interference of two nearby embedded machine foundations. Geotechnical and Geological Engineering Journal, 30(5): 1161-1181.

Ghosh, P., and Kumari, R. 2012. Seismic interference of two nearby horizontal strip anchors in layered soil. Natural Hazards, 63(2): 789-804.

Ghosh, P. 2013. Numerical studies on seismic interference of two nearby embedded shallow footings. Disaster Advances, 6(9): 19-30.

IS:5249. 1992. Method of test for determination of in-situ dynamic properties of soils. Indian Standard Institution, Manak Bhavan, New Delhi, India.

Kameswara Rao, N.S.V. 1998. Vibration analysis and foundation dynamics. Wheeler, New Delhi.

Kameswara Rao, N.S.V. 2011. Foundation design: theory and practice. Wiley, Singapore.

Karabalis, D.L., and Mohammadi, M. 1991. 3-D foundation-soil-foundation dynamics using a 3D frequency domain BEM. In:proceedings of the thirteenth conference on boundary element. Istanbul, Turkey; p. 446-456.

Karabalis, D.L., and Mohammadi, M. 1998. 3-D foundation-soil-foundation dynamics using a 3D frequency domain BEM. Soil Dynamics and Earthquake Engineering, 17: 139-152.

Kumar, J., and Reddy, C.O. 2006. Dynamic response of footing and machine with spring mounting base. Geotechnical and Geological Engineering, 24: 15-27.

Liang, C.V. 1974. Dynamic response of structures in layered soils. Ph.D. Thesis, Massachusetts Institute of Technology, Cambridge, U.S.A.

Lysmer, J., and Richart, F.E. 1966. Dynamic response of footing to vertical loading. Journal of Soil Mechanics and Foundation Division, 92(1): 65-91. 
Lysmer, J., Udaka, T., Tsai, C.F., and Seed, H.B. 1975. FLUSH-A computer program for approximate 3-d analysis of soil-structure interaction problems. Report No. EERC 75-30, Earthquake Engineering Research Center, University of California, Berkeley.

Mandal, A., Baidya, D.K., and Roy, D. 2012. Dynamic response of foundations resting on a two-layered soil underlain by a rigid layer. Geotechnical and Geological Engineering, 30: 775-786.

Qian, J., and Beskos, D.E. 1996. Harmonic wave response of two 3-D rigid surface foundations. Soil Dynamics and Earthquake Engineering, 15: 95-110.

Richart, F.E., Hall, J.R., and Woods, R.D. 1970. Vibrations of soils and foundations. Prentice-Hall, Englewood Cliffs, N.J.

Sung, T.Y. 1953. Vibrations in semi-infinite solids due to periodic surface loadings. Symposium on dynamic testing of soils, STP no. 156, ASTM, Philadelphia, 3564.

Tham, L.G., Qian, J., and Cheung, Y.K. 1998. Dynamic response of a group of flexible foundations to incident seismic waves. Soil Dynamic and Earthquake Engineering, 17: 127-137.

Triantafyllidis, T., and Prange, B. 1989. Dynamic subsoil-coupling between rigid, circular foundations on the half-space. Soil Dynamics and Earthquake Engineering, 8(1): 9-22.

Vivek, P., and Ghosh, P. 2012. Dynamic interaction of two nearby machine foundations on homogeneous soil. Geotechnical Special Publication, ASCE (GSP 225).

Wang, Y., Rajapakse, R.K.N.D., and Shah, A.H. 1991. Dynamic interaction between flexible strip foundations. Earthquake Engineering and Structural Dynamics, 20: $441-454$. 
Wang, S., and Schmid, G. 1992. Dynamic structure-soil-structure interaction by FEM and BEM. Computational Mechanics, 9: 347-357.

Warburton, G.B., Richardson, J.D., and Webster, J.J. 1971. Forced vibrations of two masses on an elastic half space. J. Appl. Mech., ASME, 38, 148-156.

Wong, H.L., and Luco, J.E. 1986. Dynamic interaction between rigid foundations in a layered half space. Soil Dynamics and Earthquake Engineering, 5(3): 149-158. 


\section{Table captions}

Table 1 Details of experimental program.

Table 2 Dynamic properties of soil under different vibrating conditions.

Table 3 Comparison of present results with Bhoumik (1989).

Table 4 Magnitude of maximum transmission ratio for different footings, S/B ratio and $\theta$ value.

\section{Figure captions}

Fig. 1. Layout of two closely spaced footing assembly.

Fig. 2. Photographic view of the experimental setup at $\mathrm{S} / \mathrm{B}=0.45$.

Fig. 3. General layout of the test setup for two closely spaced machine foundations.

Fig. 4. Variation of displacement amplitude with frequency for dynamic response of isolated footings (a) F1 ( $\mathrm{I}_{10} \mathrm{~S}_{0} \mathrm{E}_{16}, \mathrm{I}_{10} \mathrm{~S}_{0} \mathrm{E}_{24}$ and $\left.\mathrm{I}_{10} \mathrm{~S}_{0} \mathrm{E}_{32}\right)$ and (b) $\mathrm{F} 2\left(\mathrm{I}_{20} \mathrm{~S}_{0} \mathrm{E}_{16}\right.$, $\mathrm{I}_{20} \mathrm{~S}_{0} \mathrm{E}_{24}$ and $\left.\mathrm{I}_{20} \mathrm{~S}_{0} \mathrm{E}_{32}\right)$.

Fig. 5. Variation of magnification factor with frequency ratio for dynamic response of isolated footings (a) F1 ( $\mathrm{I}_{10} \mathrm{~S}_{0} \mathrm{E}_{16}, \mathrm{I}_{10} \mathrm{~S}_{0} \mathrm{E}_{24}$ and $\left.\mathrm{I}_{10} \mathrm{~S}_{0} \mathrm{E}_{32}\right)$ and (b) $\mathrm{F} 2\left(\mathrm{I}_{20} \mathrm{~S}_{0} \mathrm{E}_{16}\right.$, $\mathrm{I}_{20} \mathrm{~S}_{0} \mathrm{E}_{24}$ and $\left.\mathrm{I}_{20} \mathrm{~S}_{0} \mathrm{E}_{32}\right)$.

Fig. 6. Comparison of the present results with Kumar and Reddy (2006) for (a) soil stiffness and (b) damping ratio.

Fig. 7. Dynamic response due to interaction between F1 (active) and F1 (passive) footings.

Fig. 8. Dynamic responses due to interaction between F1 (active) and F2 (passive) footings. 
Fig. 9. Dynamic response due to interaction between F2 (active) and F1 (passive) footings.

Fig. 10. Dynamic response due to interaction between F2 (active) and F2 (passive) footings.

Fig. 11. Dynamic response of passive footing in different combination for different eccentric force settings at $\mathrm{S} / \mathrm{B}=0.45$.

Fig. 12. Variation of transmission ratio with frequency ratio due to interaction between F1 (active) and F1 (passive) footings.

Fig. 13. Variation of transmission ratio with frequency ratio due to interaction between F1 (active) and F2 (passive) footings.

Fig. 14. Variation of transmission ratio with frequency ratio due to interaction between F2 (active) and F1 (passive) footings.

Fig. 15. Variation of transmission ratio with frequency ratio due to interaction between F2 (active) and F2 (passive) footings. 


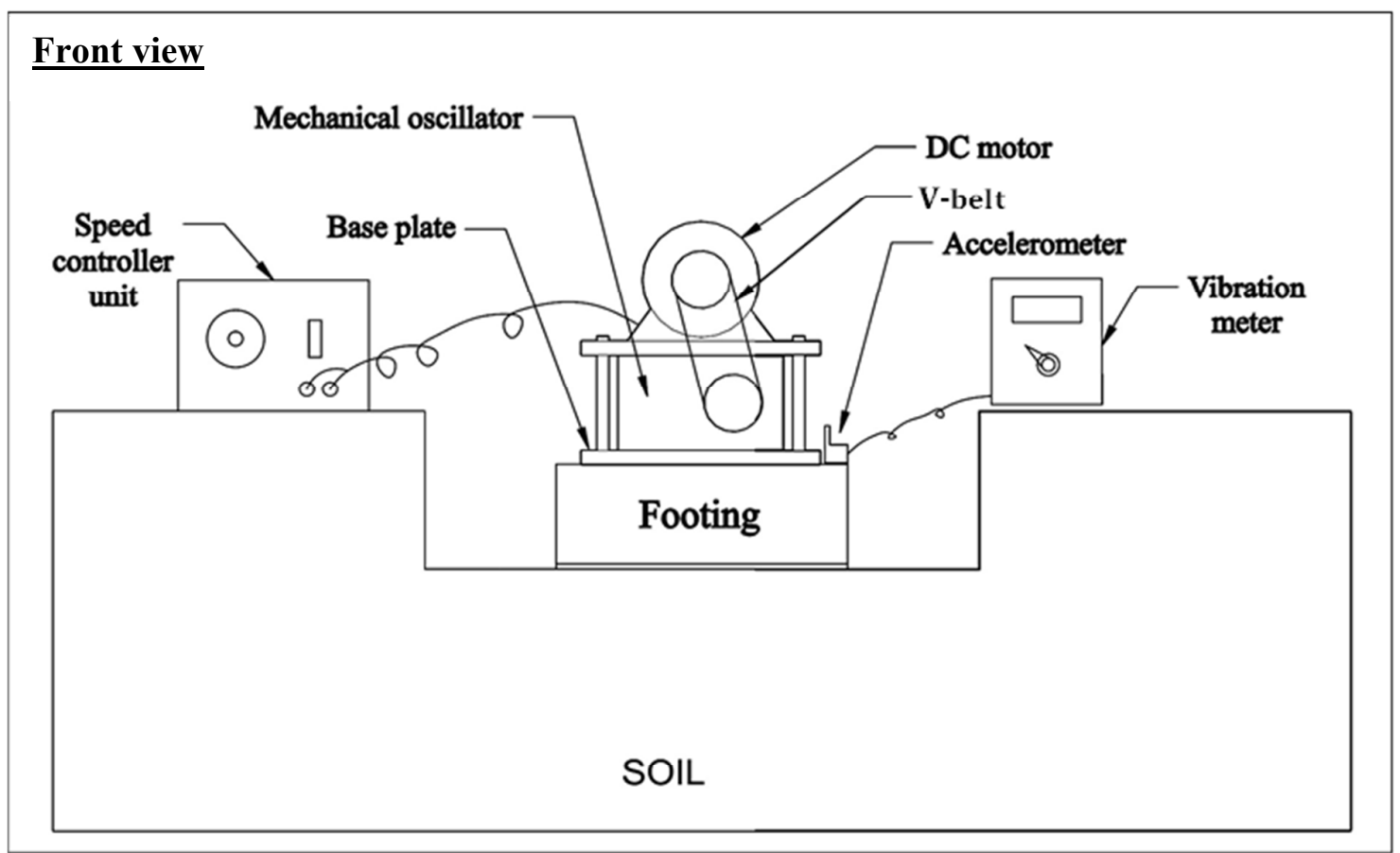

(a)

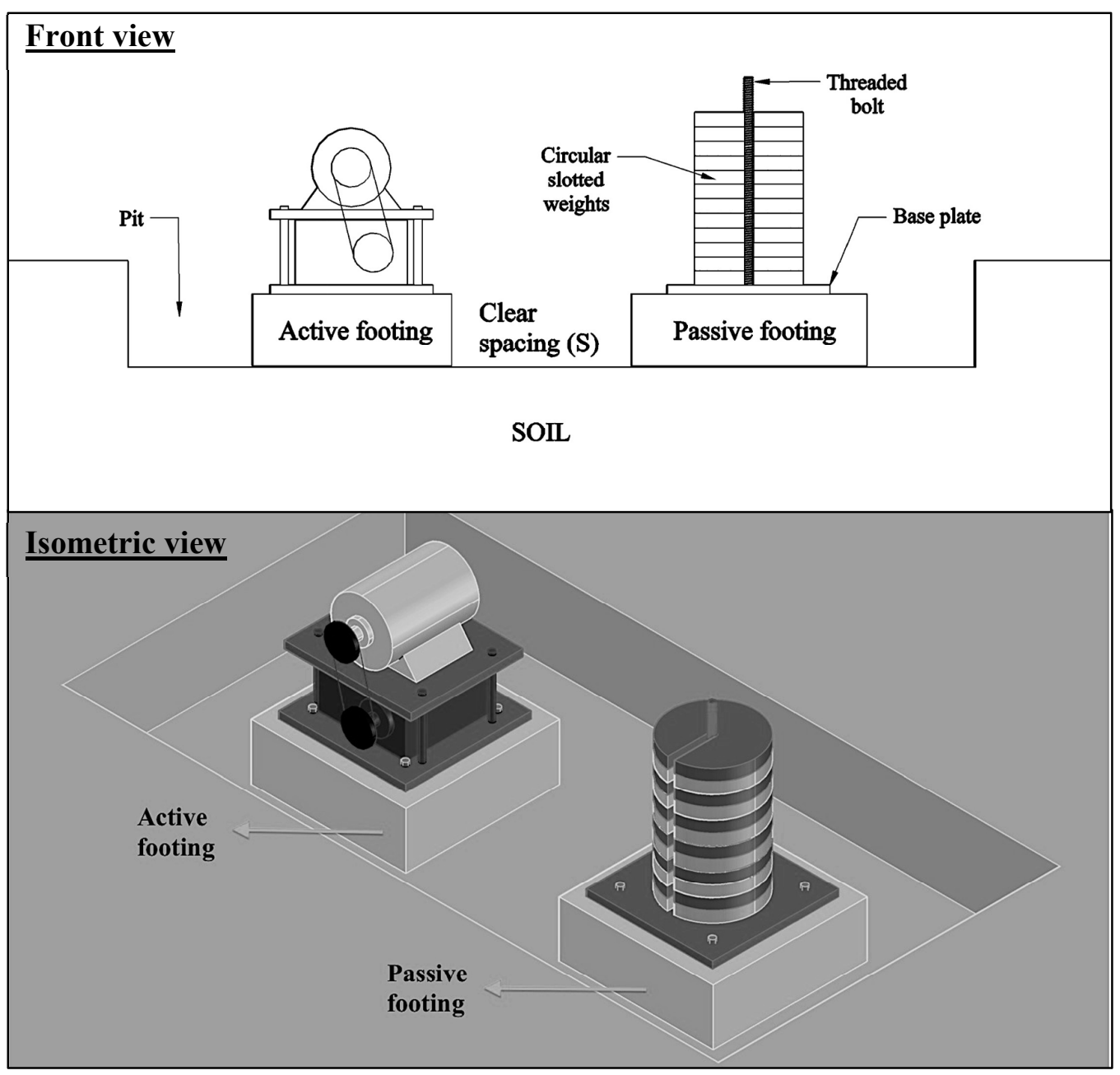

(b)

Fig. 1: Layout of two closely spaced footing assembly

https://mc06.manuscriptcentral.com/cgj-pubs 


\section{Canadian Geotechnical Journal}

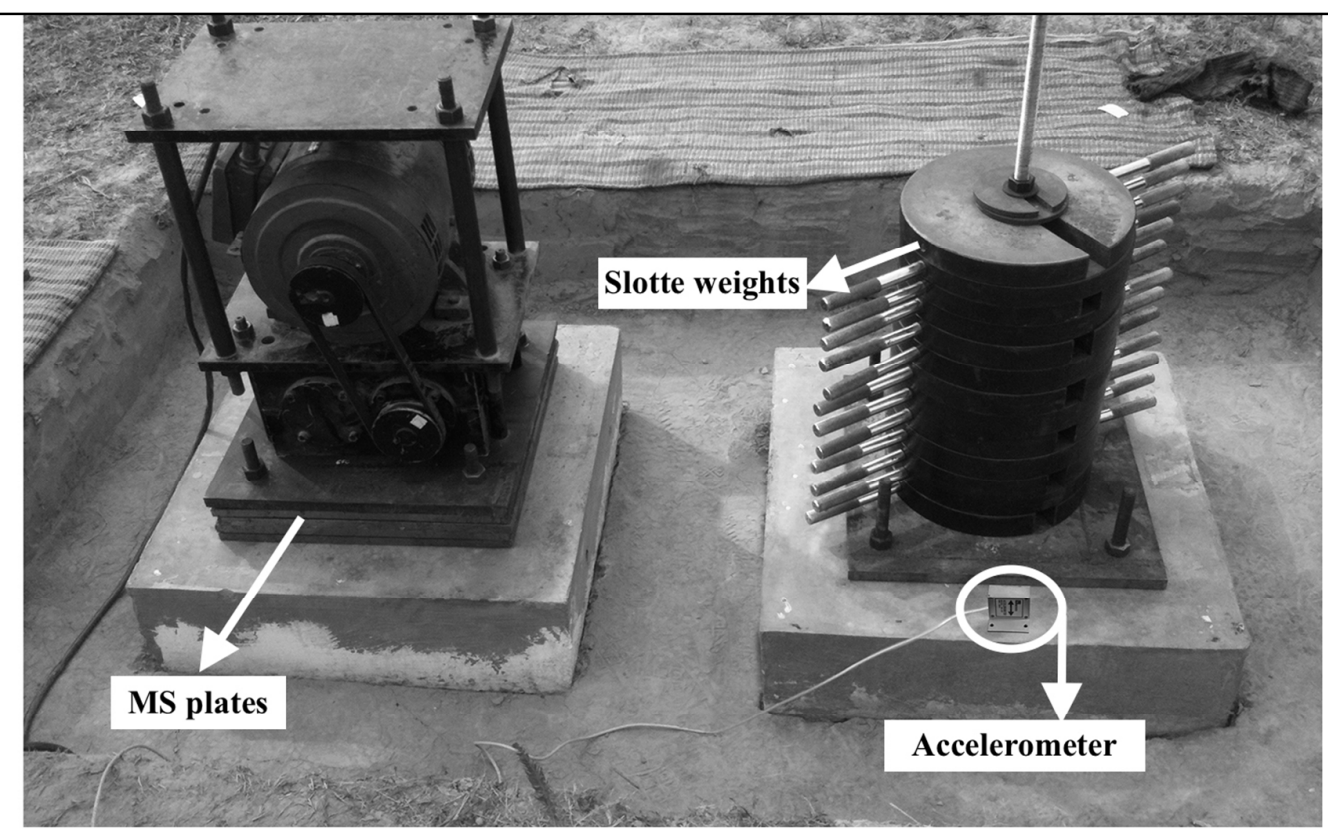

Pit (P2) : Active footing (F2) and passive footing (F2) with S/B = 0.45

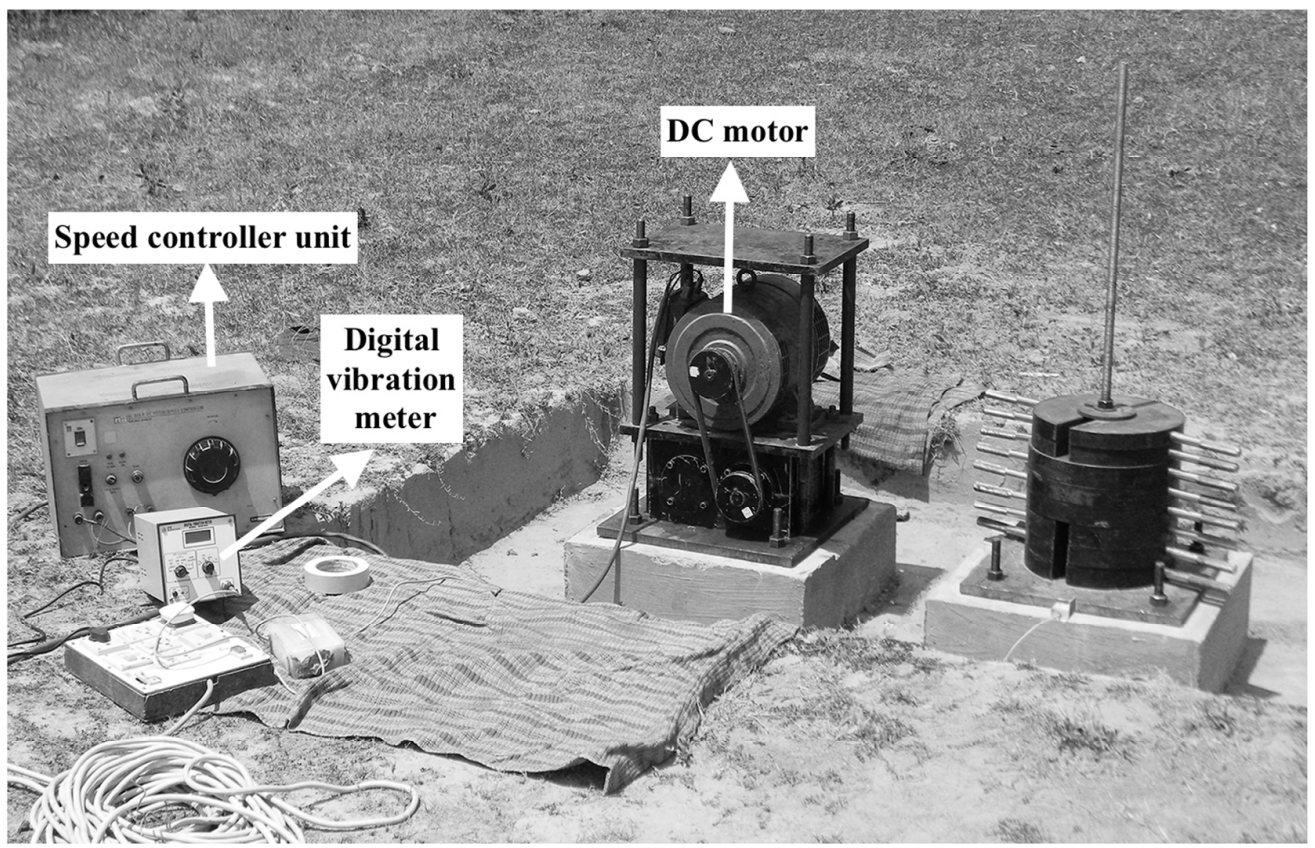

Pit (P1) : Active footing (F1) and passive footing (F1) with $\mathrm{S} / \mathrm{B}=0.45$ 


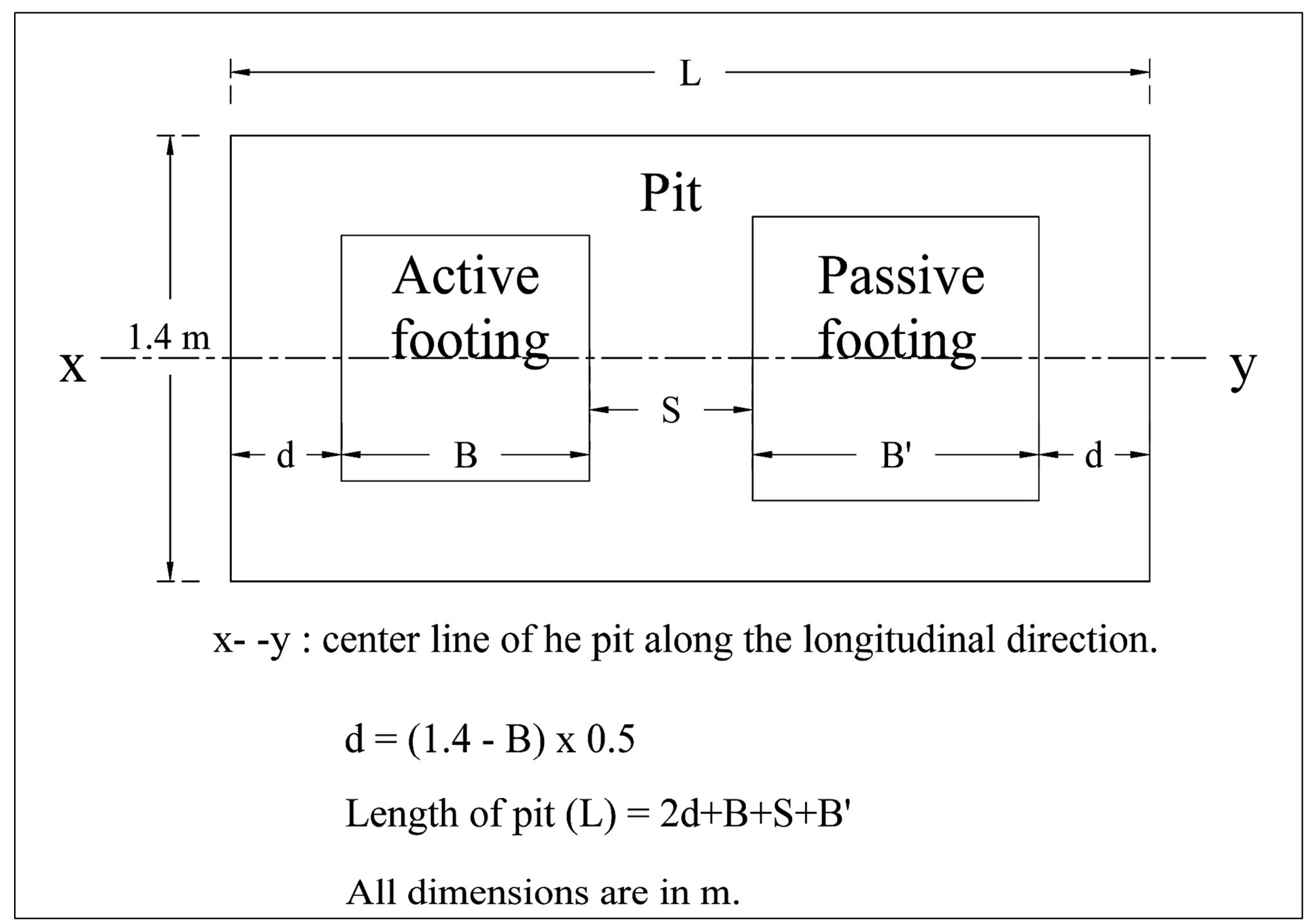

Fig. 3. General layout of the test setup for two closely spaced machine foundations 

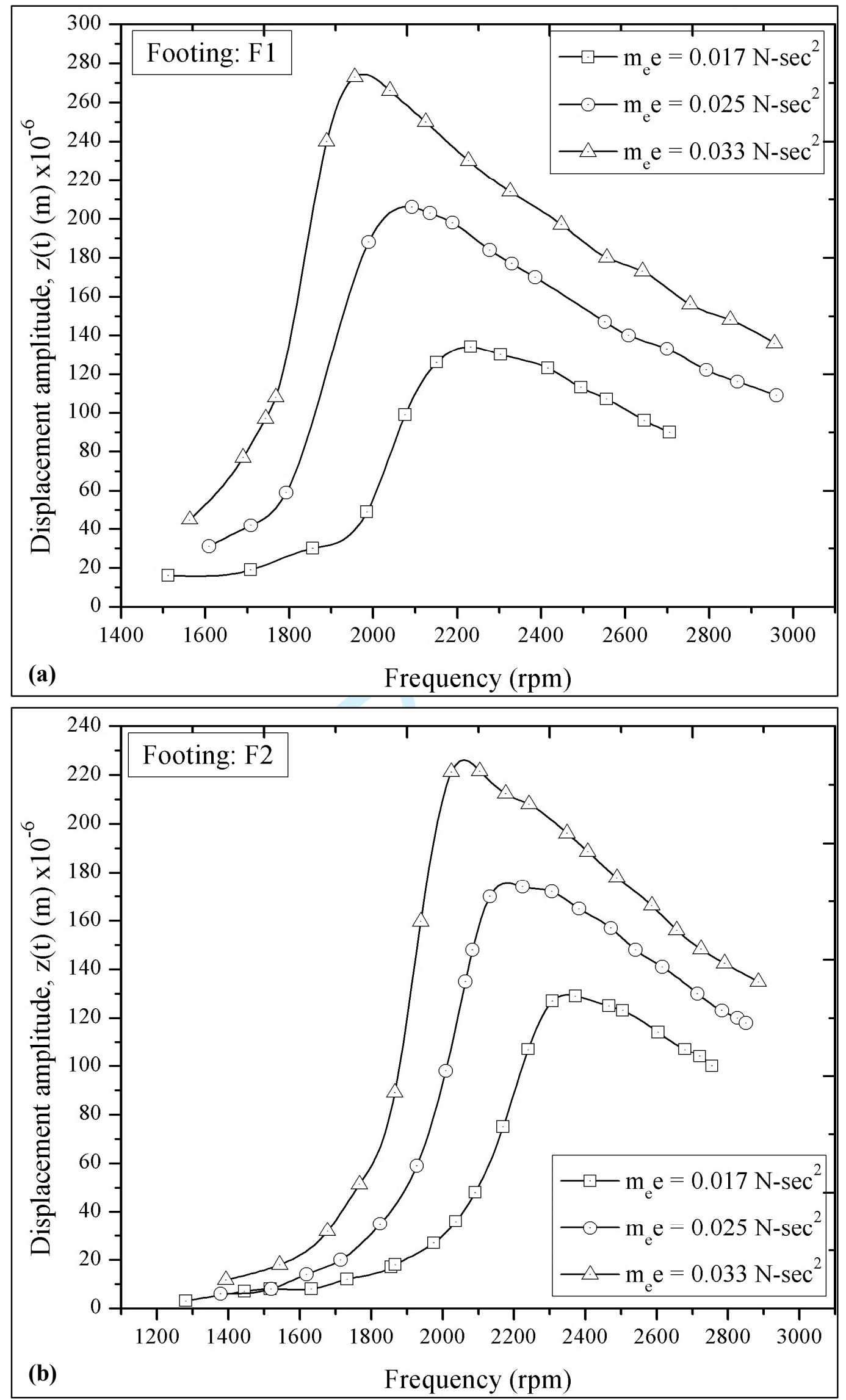

Fig. 4. Variation of displacement amplitude with frequency ratio for the dynamic response of isolated footings (a) $F 1\left(I_{10} S_{0} E_{16}, I_{10} S_{0} E_{24}\right.$ and $\left.I_{10} S_{0} E_{32}\right)$ and (b) F2 

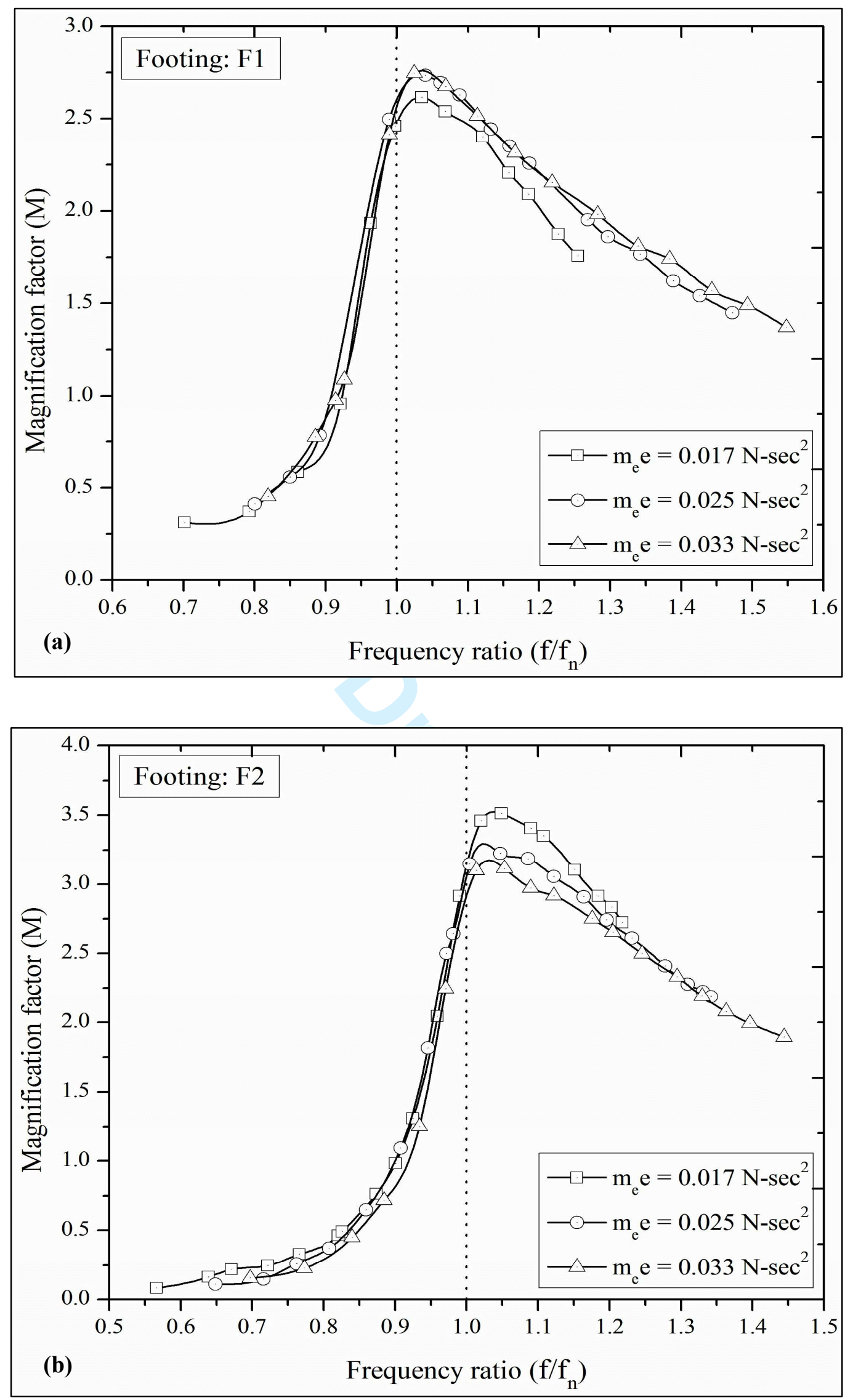

Fig. 5. Variation of magnification factor with frequency ratio for the dynamic response of isolated footings (a) $F 1\left(I_{10} S_{0} E_{16}, I_{10} S_{0} E_{24}\right.$ and $\left.I_{10} S_{0} E_{32}\right)$ and (b) F2 


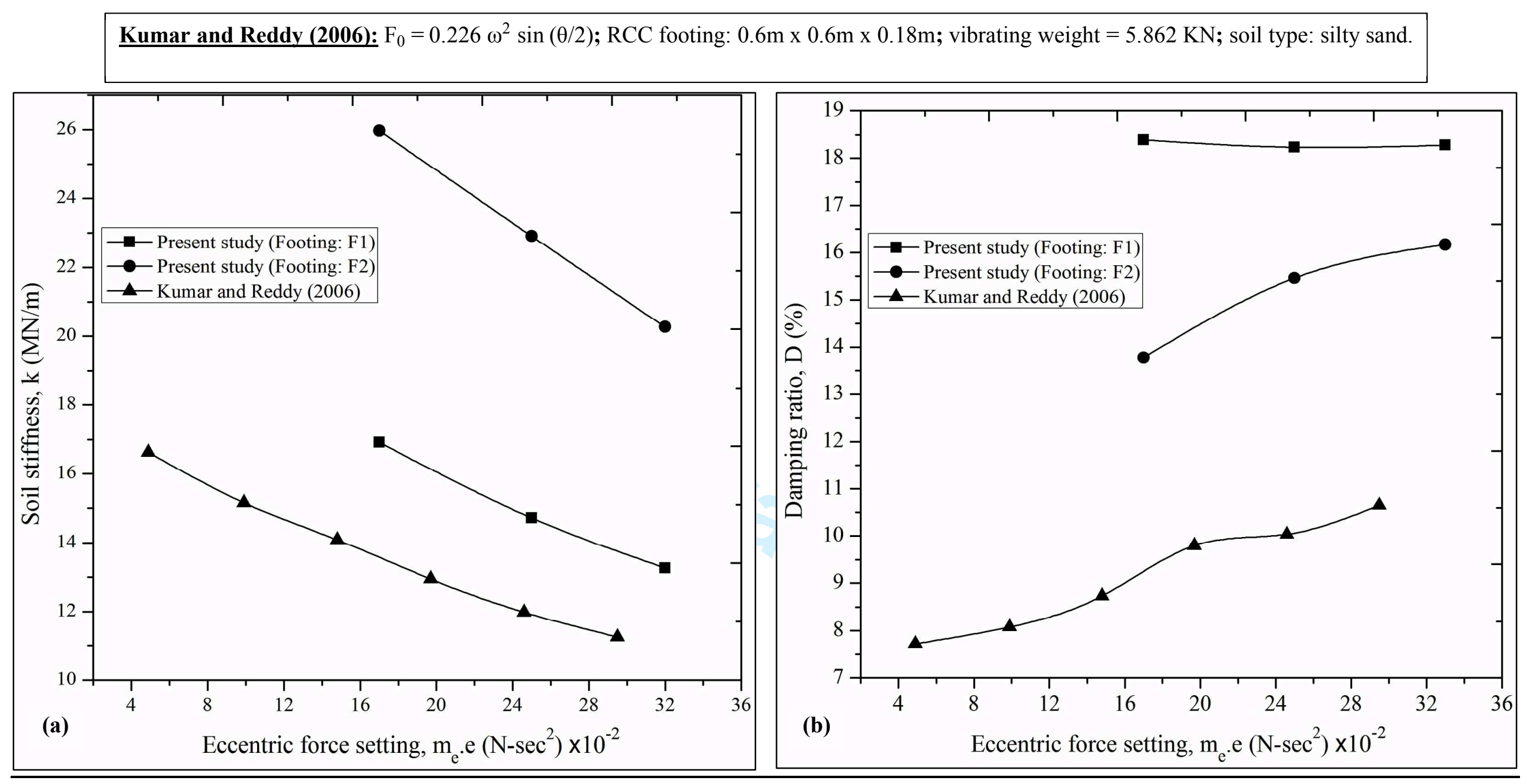

Fig. 6. Comparison of the present results with Kumar and Reddy (2006) (a) soil stiffness and (b) damping ratio 


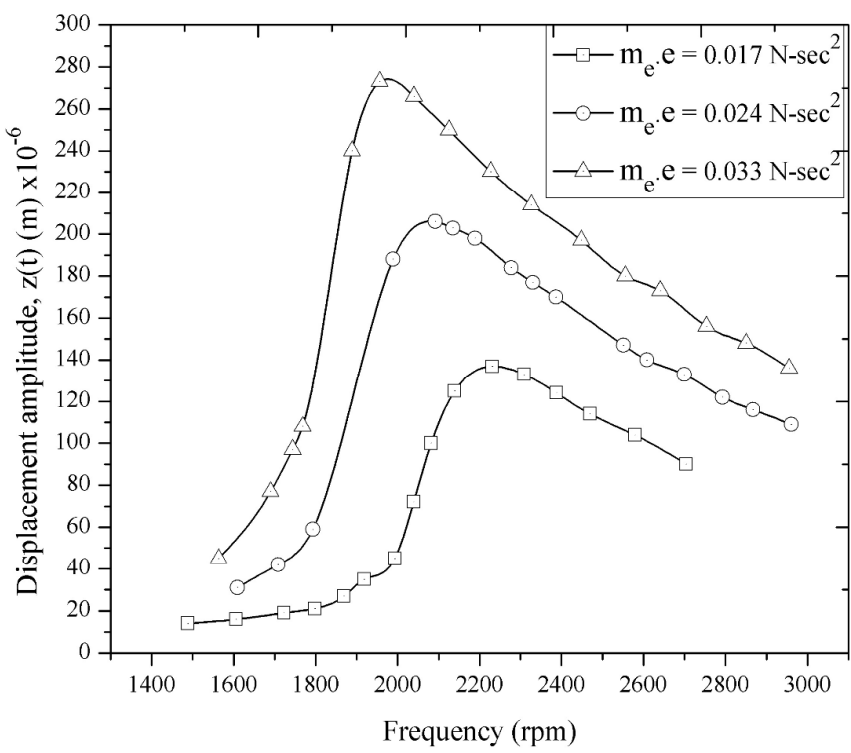

(a) Active footing response for: $I_{11} S_{0.45} E_{16}$, $I_{11} S_{0.90} E_{16}, I_{11} S_{1.35} E_{16}, I_{11} S_{0.45} E_{24}, I_{11} S_{0.90} E_{24}$, $I_{11} S_{1.35} E_{24}, I_{11} S_{0.45} E_{32}, I_{11} S_{0.90} E_{32}$ and $I_{11} S_{1.35} E_{32}$

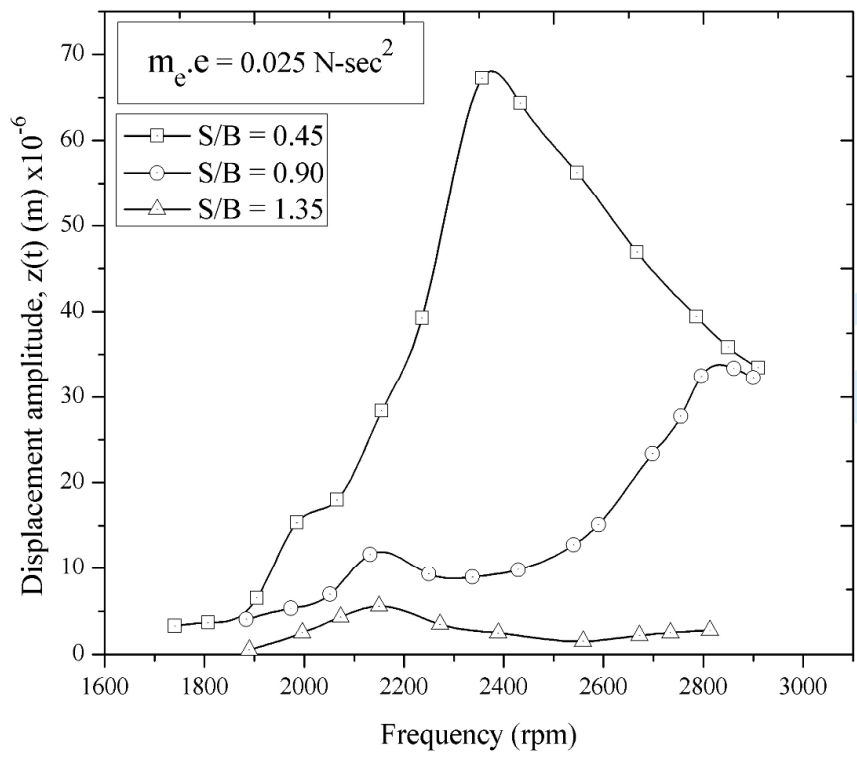

(c) Passive footing response for: $\mathrm{I}_{11} S_{0.45} E_{24}$, $I_{11} S_{0.90} E_{24}$ and $I_{11} S_{1.35} E_{24}$

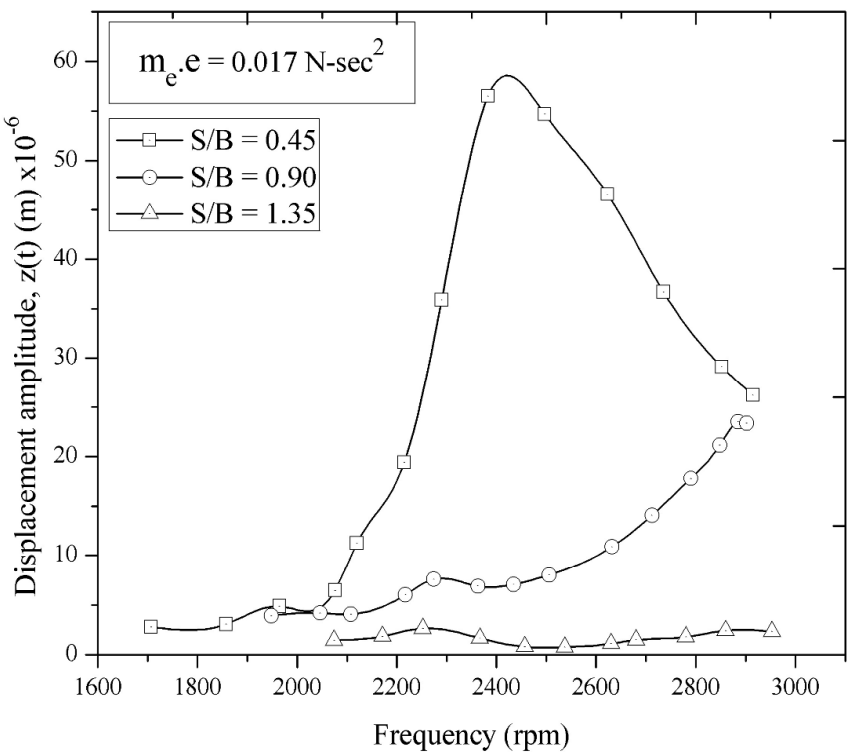

(b) Passive footing response for: $I_{11} S_{0.45} E_{16}$, $I_{11} S_{0.90} E_{16}$ and $I_{11} S_{1.35} E_{16}$

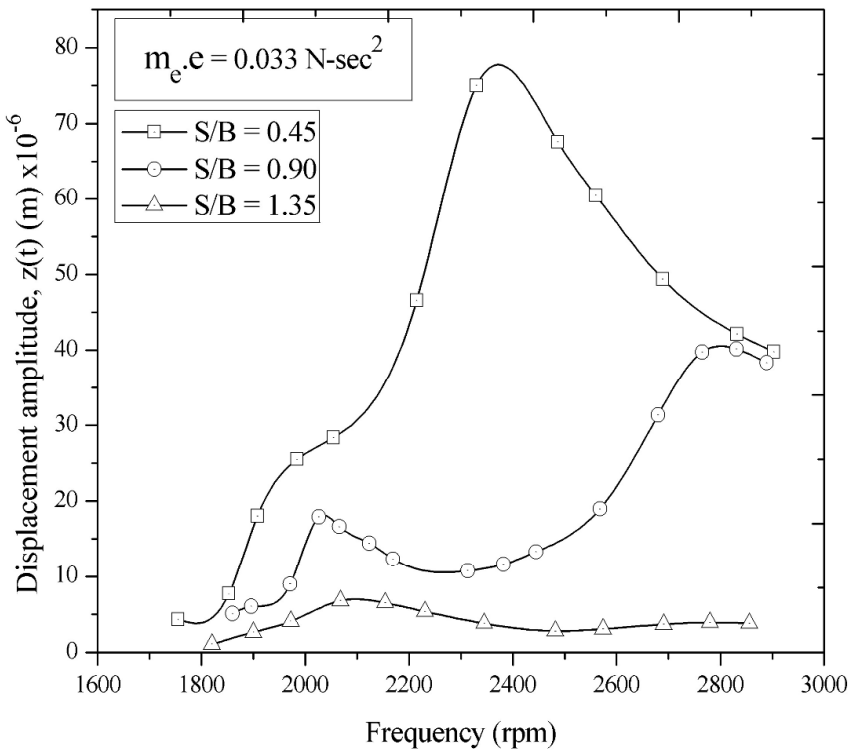

(d) Passive footing response for: $I_{11} S_{0.45} E_{32}$, $I_{11} S_{0.90} E_{32}$ and $I_{11} S_{1.35} E_{32}$

Fig. 7. Dynamic response due to interaction between F1 (active) and F1 (passive) footings 


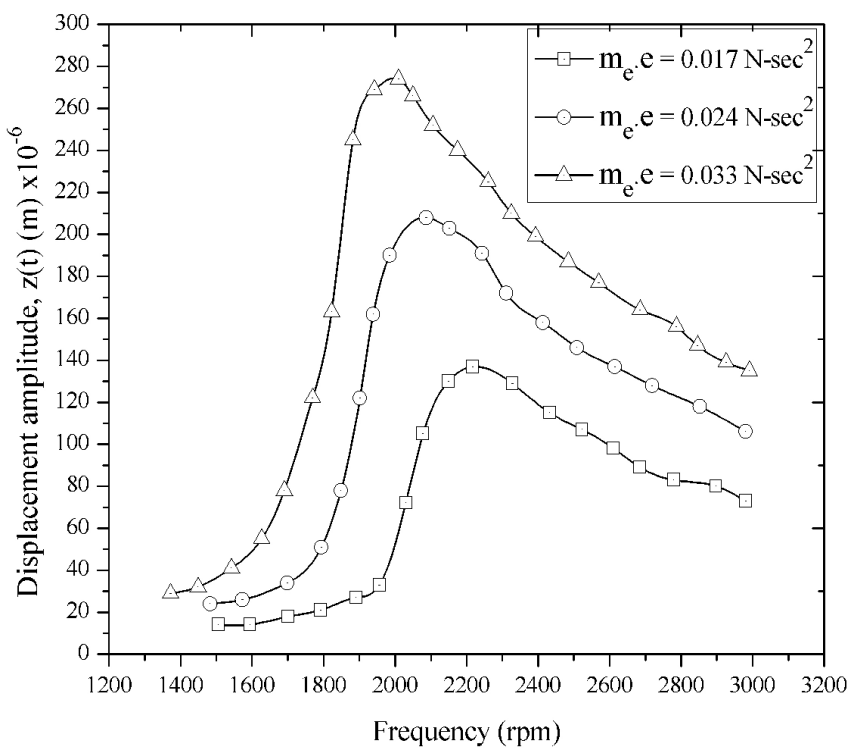

(a) Active footing response for $\mathrm{I}_{12} \mathrm{~S}_{0.45} \mathrm{E}_{16}$, $I_{12} S_{0.90} E_{16}, I_{12} S_{1.35} E_{16}, I_{12} S_{0.45} E_{24}, I_{12} S_{0.90} E_{24}$, $I_{12} S_{1.35} E_{24}, I_{12} S_{0.45} E_{32}, I_{12} S_{0.90} E_{32}$ and $I_{12} S_{1.35} E_{32}$

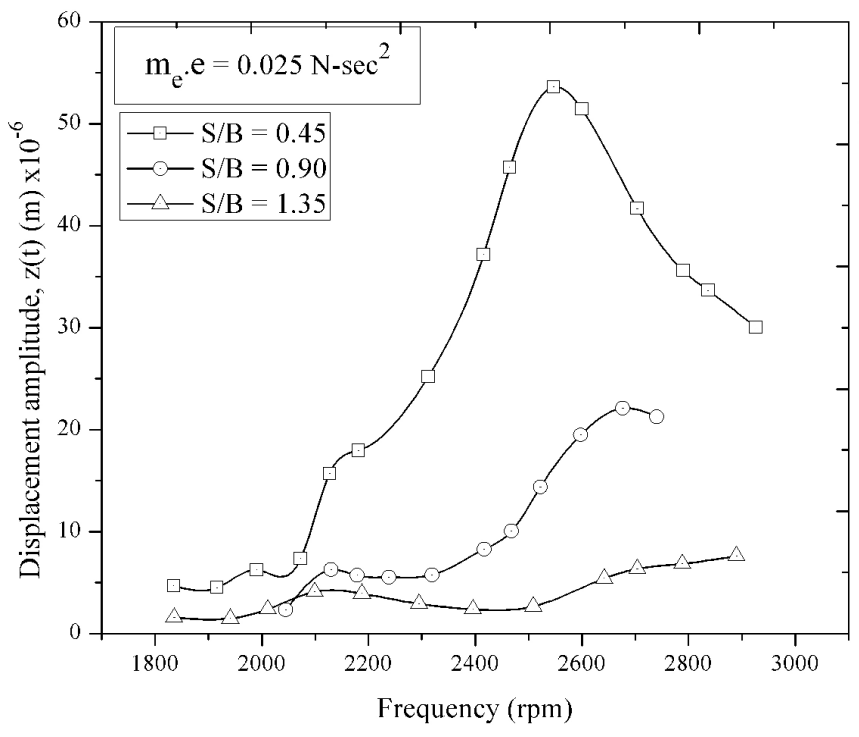

(c) Passive footing response for $\mathrm{I}_{12} \mathrm{~S}_{0.45} \mathrm{E}_{24}$, $\mathrm{I}_{12} \mathrm{~S}_{0.90} \mathrm{E}_{24}$ and $\mathrm{I}_{12} \mathrm{~S}_{1.35} \mathrm{E}_{24}$

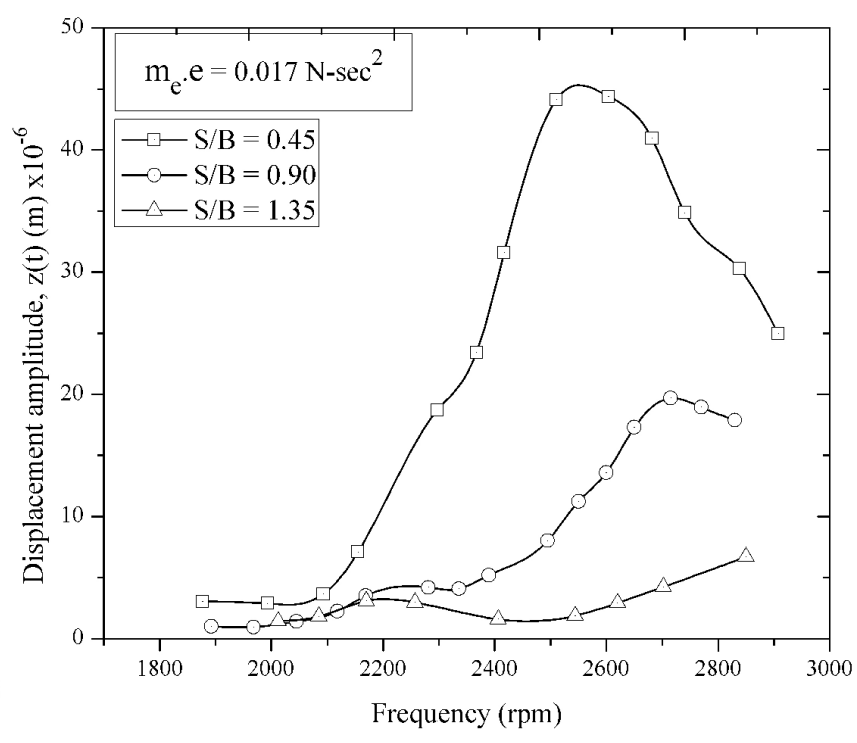

(b) Passive footing response for $\mathrm{I}_{12} \mathrm{~S}_{\mathbf{0 . 4 5}} \mathrm{E}_{16}$, $I_{12} S_{0.90} E_{16}$ and $I_{12} S_{1.35} E_{16}$

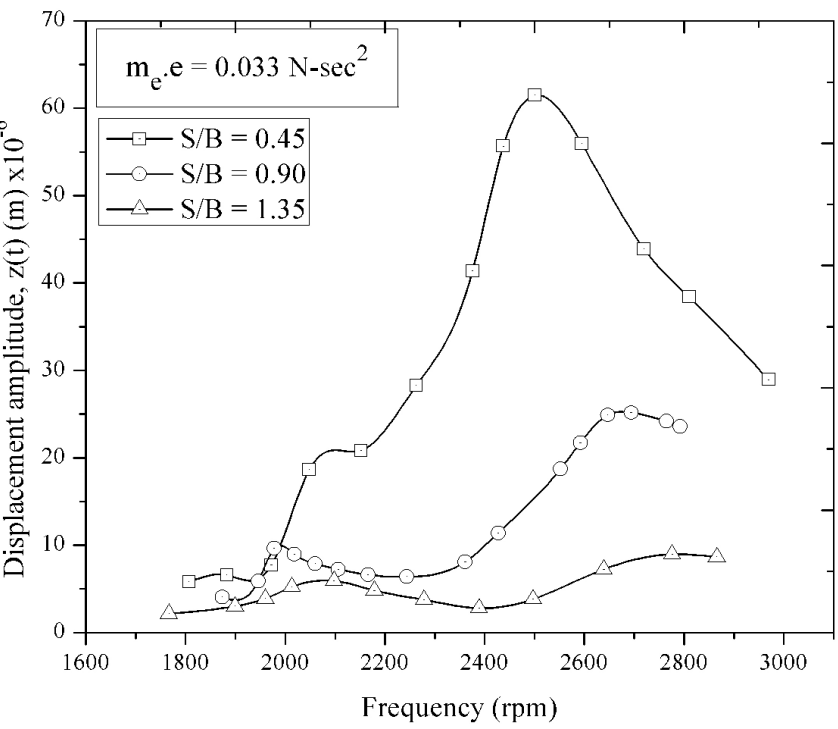

(d) Passive footing response for $\mathrm{I}_{12} \mathrm{~S}_{0.45} \mathrm{E}_{32}$, $I_{12} S_{0.90} E_{32}$ and $I_{12} S_{1.35} E_{32}$

Fig. 8. Dynamic response due to interaction between F1 (active) and F2 (passive) footings 


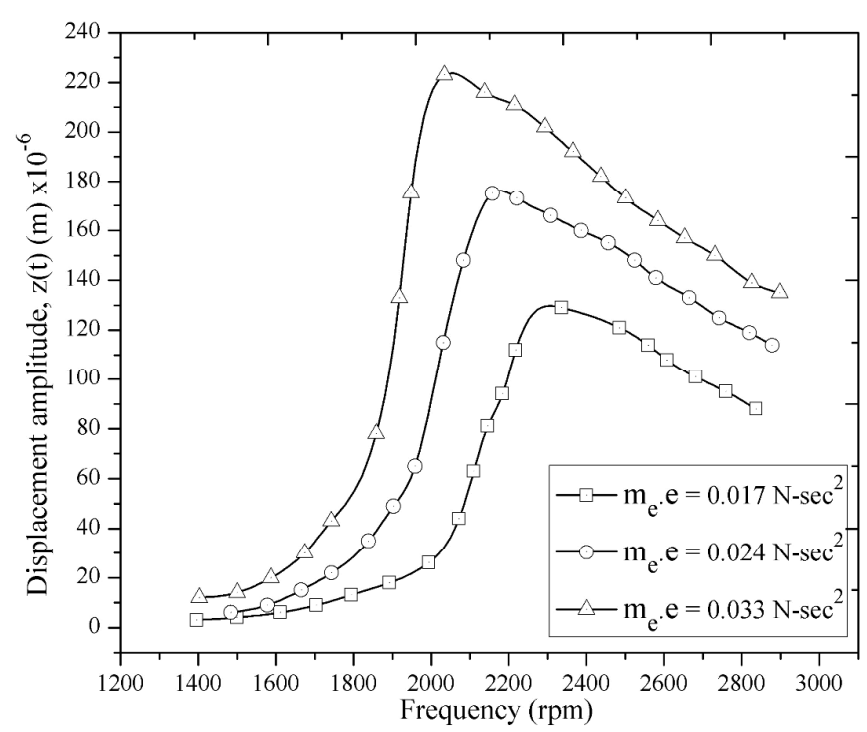

(a) Active footing response for $I_{21} S_{0.45} E_{16}$, $I_{21} S_{0.90} E_{16}, I_{21} S_{1.35} E_{16}, I_{21} S_{1.80} E_{16}, I_{21} S_{0.45} E_{24}$, $I_{21} S_{0.90} E_{24}, I_{21} S_{1.35} E_{24}, I_{21} S_{1.80} E_{24}, I_{21} S_{0.45} E_{32}$, $I_{21} S_{0.90} E_{32}, I_{21} S_{1.35} E_{32}$ and $I_{21} S_{1.80} E_{32}$.

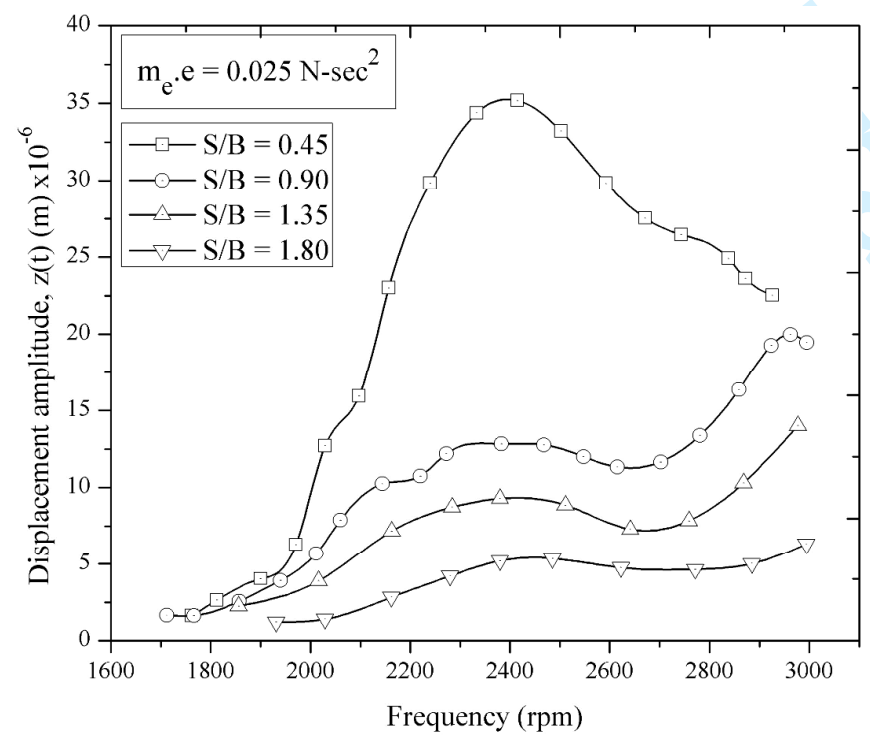

(c) Passive footing response for $I_{21} S_{0.45} E_{24}$, $I_{21} S_{0.90} E_{24}, I_{21} S_{1.35} E_{24}$ and $I_{21} S_{1.80} E_{24}$

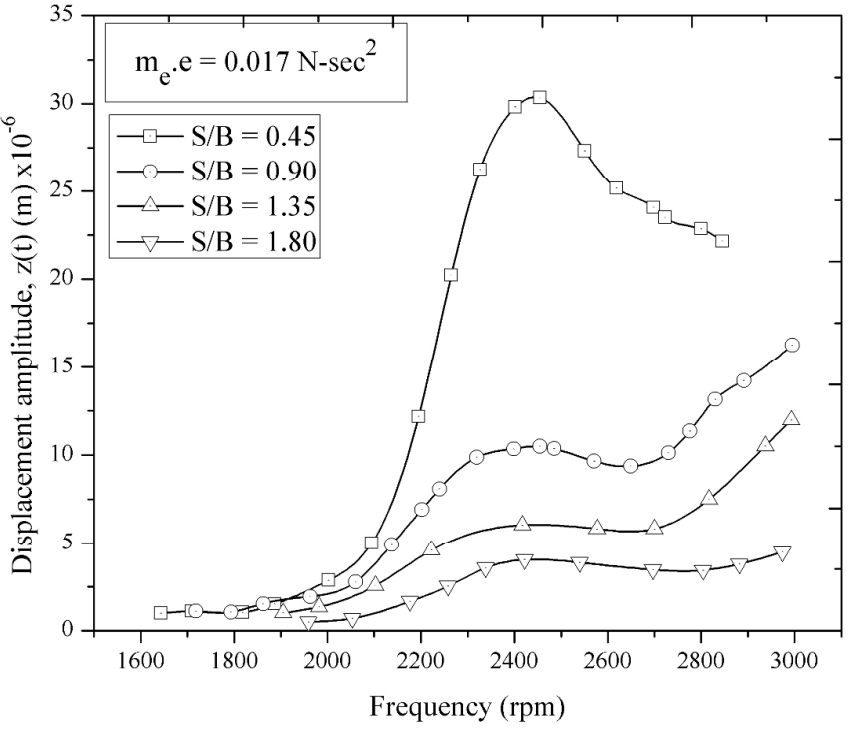

(b) Passive footing response for $\mathrm{I}_{21} \mathrm{~S}_{0.45} \mathrm{E}_{16}$, $I_{21} S_{0.90} E_{16}, I_{21} S_{1.35} E_{16}$ and $I_{21} S_{1.80} E_{16}$

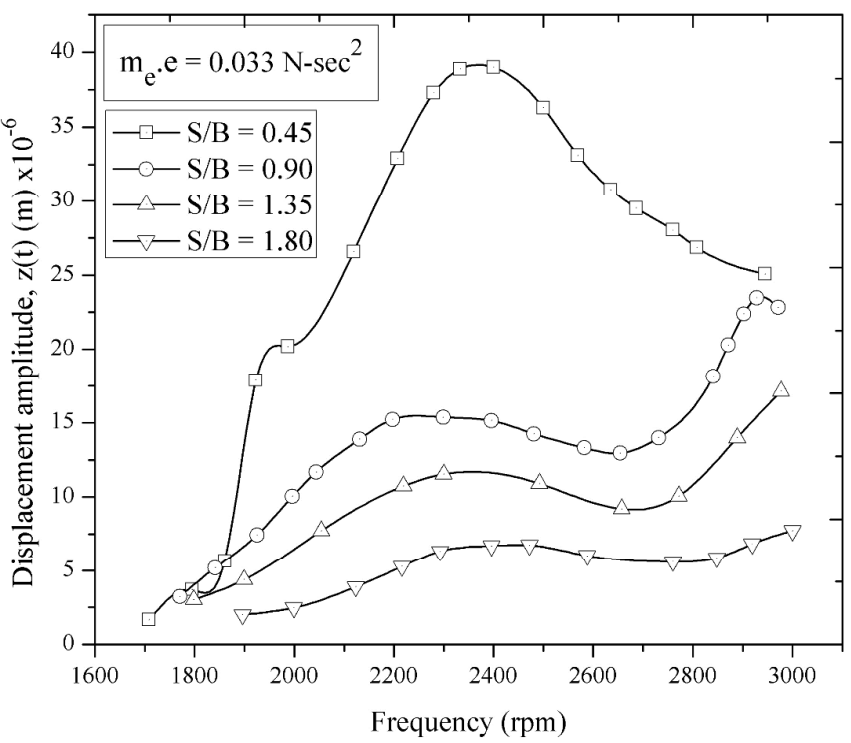

(d) Passive footing response for $I_{21} S_{0.45} E_{32}$, $I_{21} S_{0.90} E_{32}, I_{21} S_{1.35} E_{32}$ and $I_{21} S_{1.80} E_{32}$

Fig. 9. Dynamic response due to interaction between F2 (active) and F1 (passive) footings 


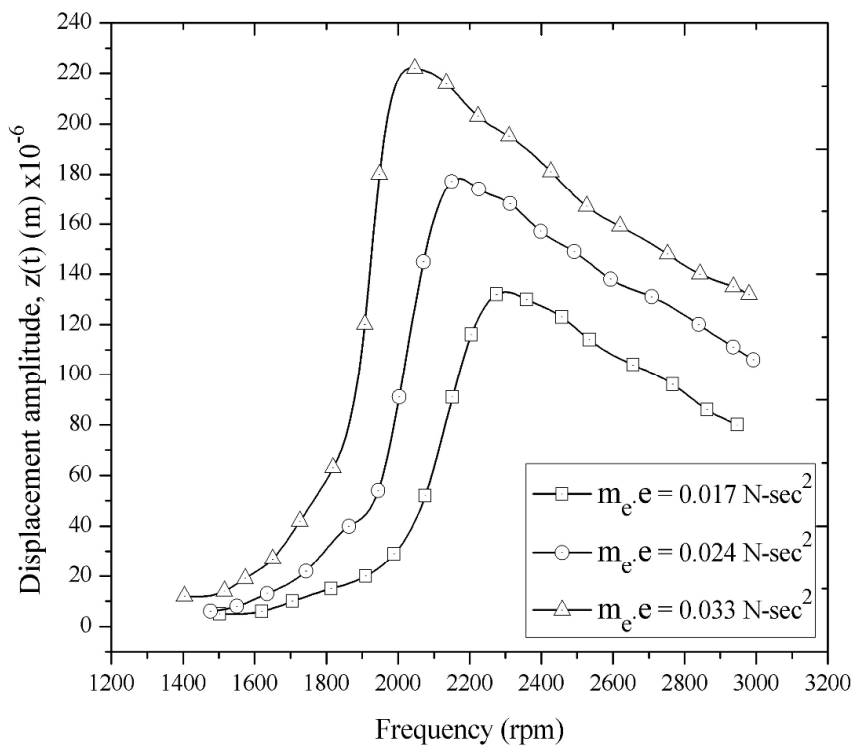

(a) Active footing response for $\mathrm{I}_{22} \mathrm{~S}_{0.45} \mathbf{E}_{16}$,

$I_{22} S_{0.90} E_{16}, I_{22} S_{1.35} E_{16}, I_{22} S_{0.45} E_{24}, I_{22} S_{0.90} E_{24}$, $I_{22} S_{1.35} E_{24}, I_{22} S_{0.45} E_{32}, I_{22} S_{0.90} E_{32}$ and $I_{22} S_{1.35} E_{32}$

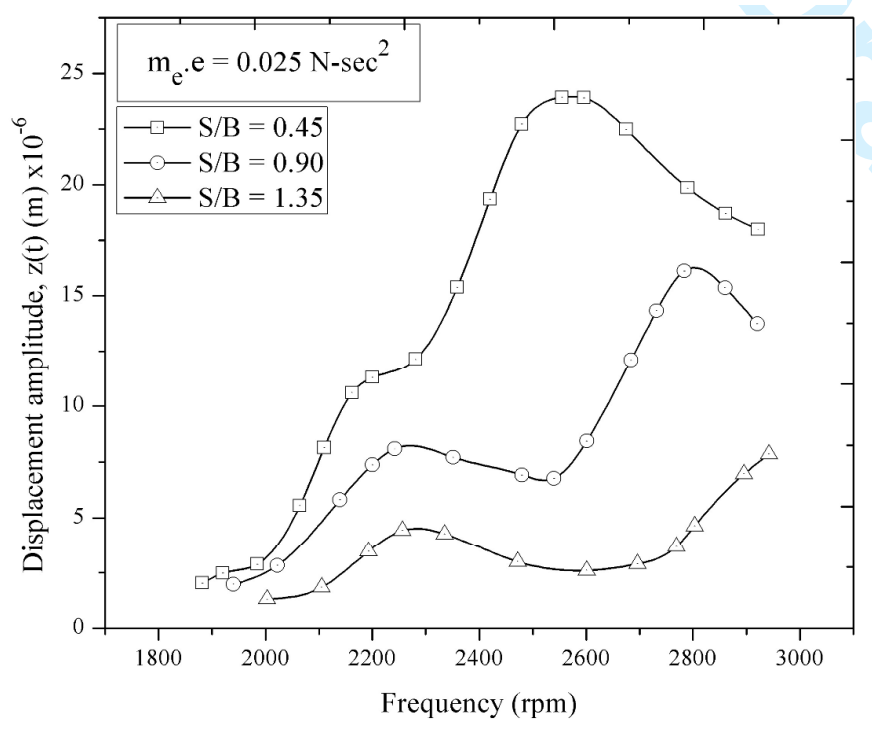

(c) Passive footing response for $I_{22} S_{0.45} E_{24}$, $I_{22} S_{0.90} E_{24}$ and $I_{22} S_{1.35} E_{24}$

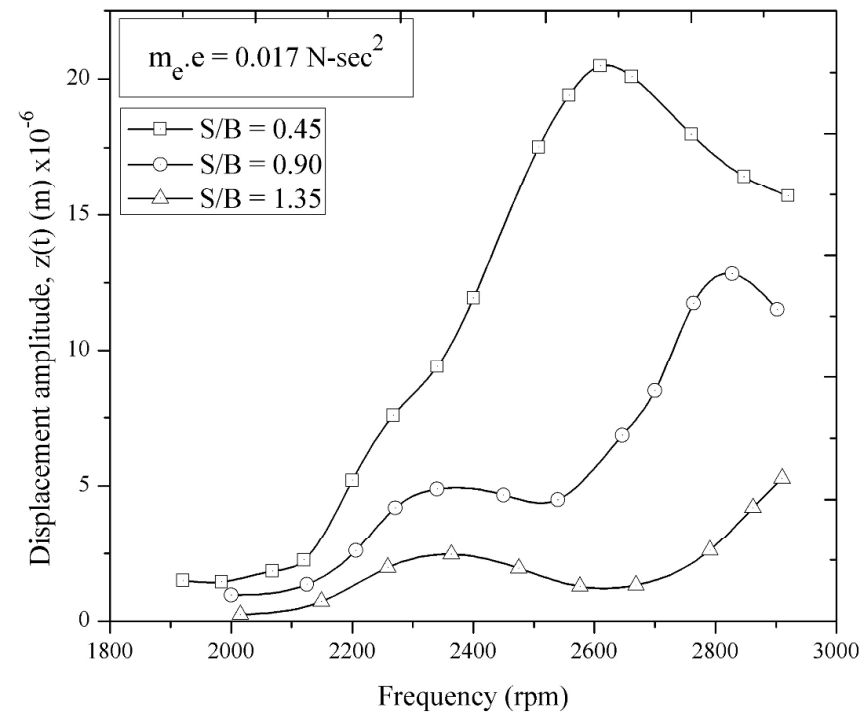

(b) Passive footing response for $I_{22} S_{0.45} E_{16}$, $I_{22} S_{0.90} E_{16}$ and $I_{22} S_{1.35} E_{16}$

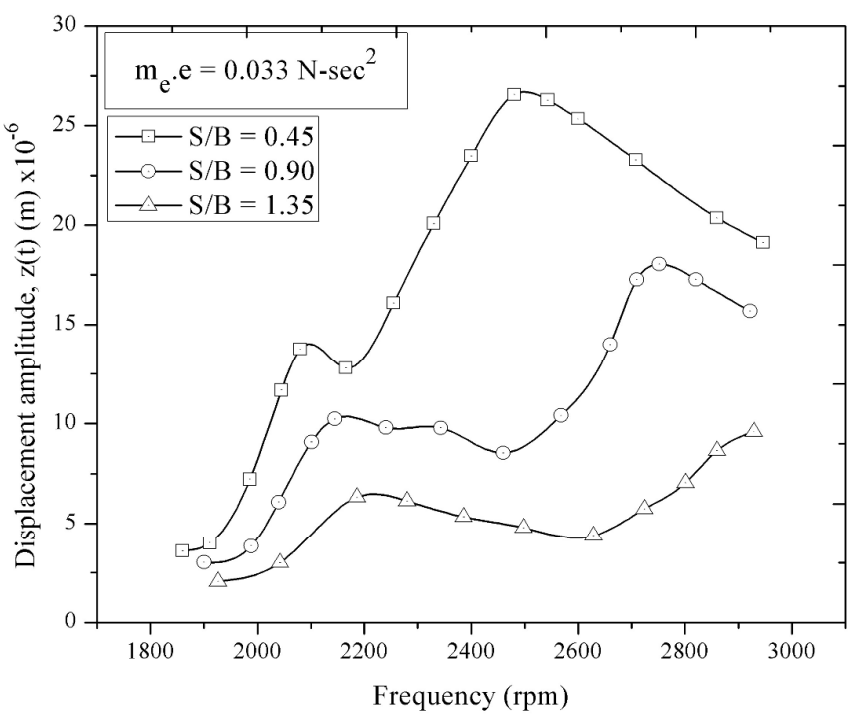

(d) Passive footing response for $I_{22} S_{0.45} E_{32}$, $I_{22} S_{0.90} E_{32}$ and $I_{22} S_{1.35} E_{32}$

Fig. 10. Dynamic response due to interaction between F2 (active) and F2 (passive) footings 


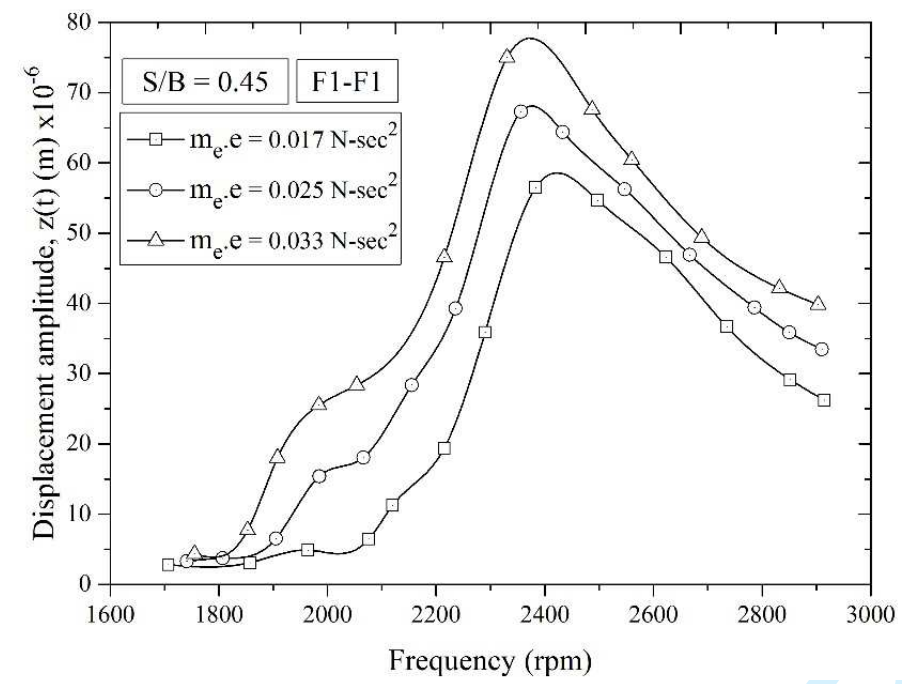

(a) Passive footing (F1) response for:

$I_{11} S_{0.45} E_{16,} I_{11} S_{0.45} E_{24}$ and $I_{11} S_{0.45} E_{32}$

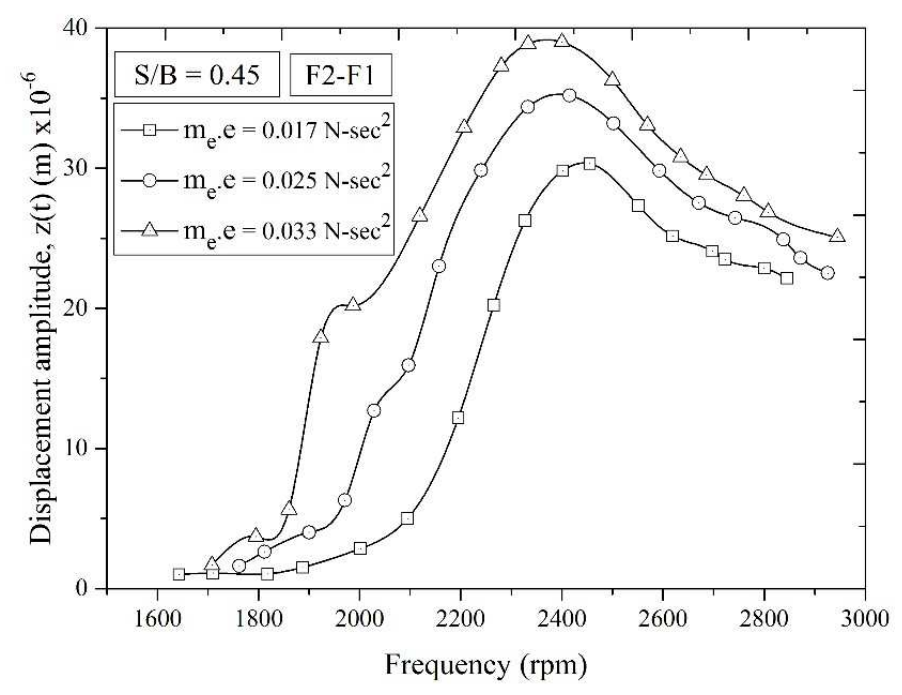

(c) Passive footing response (F1) for:

$\mathbf{I}_{21} \mathbf{S}_{\mathbf{0 . 4 5}} \mathbf{E}_{16,} \mathbf{I}_{21} \mathbf{S}_{0.45} \mathbf{E}_{24}$ and $\mathbf{I}_{21} \mathbf{S}_{0.45} \mathbf{E}_{32}$

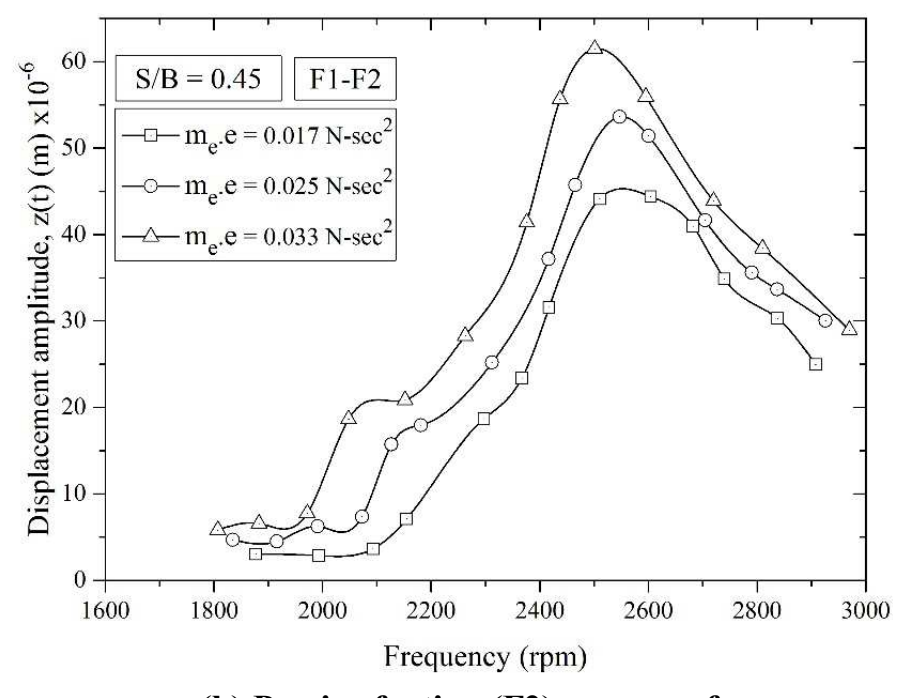

(b) Passive footing (F2) response for:

$I_{12} S_{0.45} E_{16 .} I_{12} S_{0.45} E_{24}$ and $I_{12} S_{0.45} E_{32}$

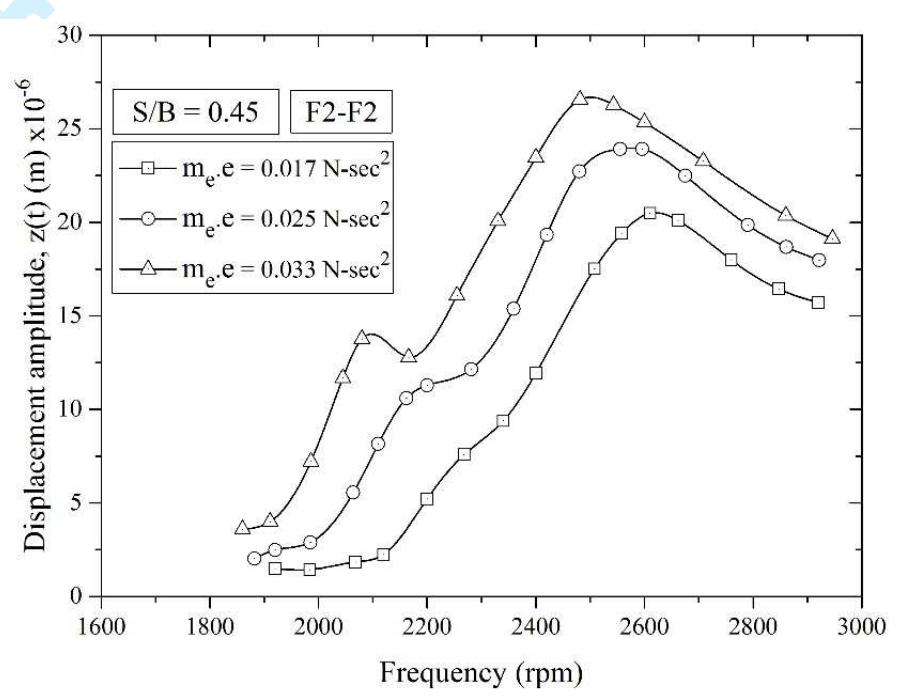

(d) Passive footing response (F2) for:

$I_{22} S_{0.45} E_{16}, I_{22} S_{0.45} E_{24}$ and $I_{22} S_{0.45} E_{32}$

Fig. 11. Dynamic response of passive footing in different combinations for different eccentric force settings at $S / B=0.45$ 


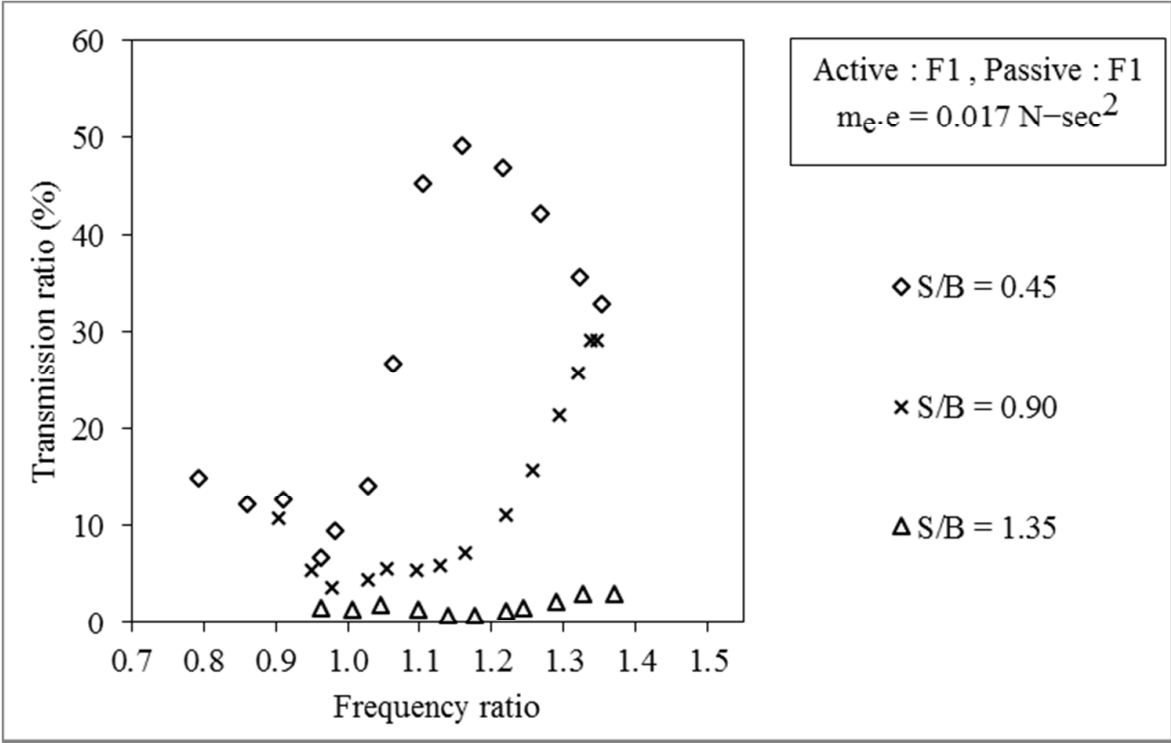

(a) For $I_{11} S_{0.45} E_{16}, I_{11} S_{0.90} E_{16}$ and $I_{11} S_{1.35} E_{16}$

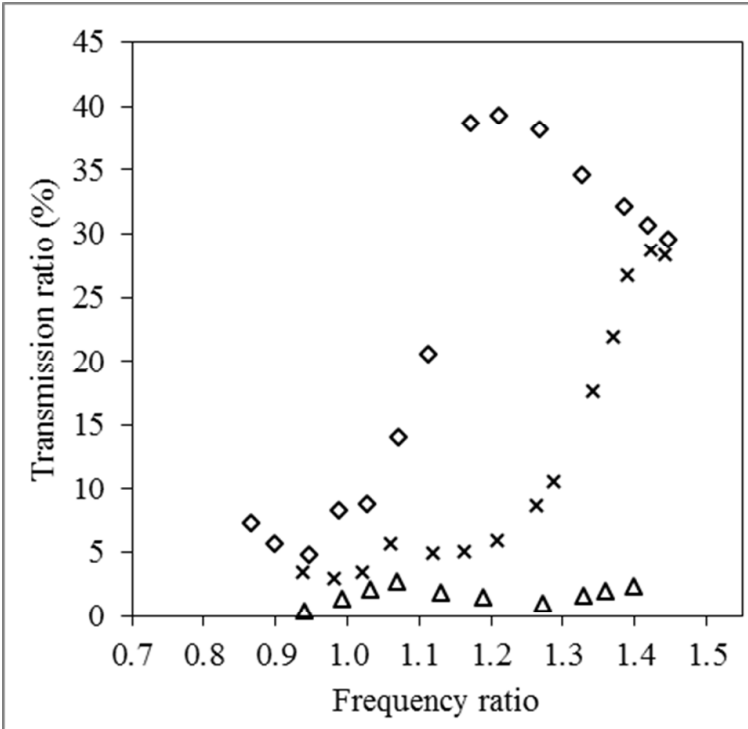

Active : F1, Passive : F1 $\mathrm{m}_{\mathrm{e}} \cdot \mathrm{e}=0.025 \mathrm{~N}-\mathrm{sec}^{2}$

(b) For $I_{11} S_{0.45} E_{24}, I_{11} S_{0.90} E_{24}$ and $I_{11} S_{1.35} E_{24}$

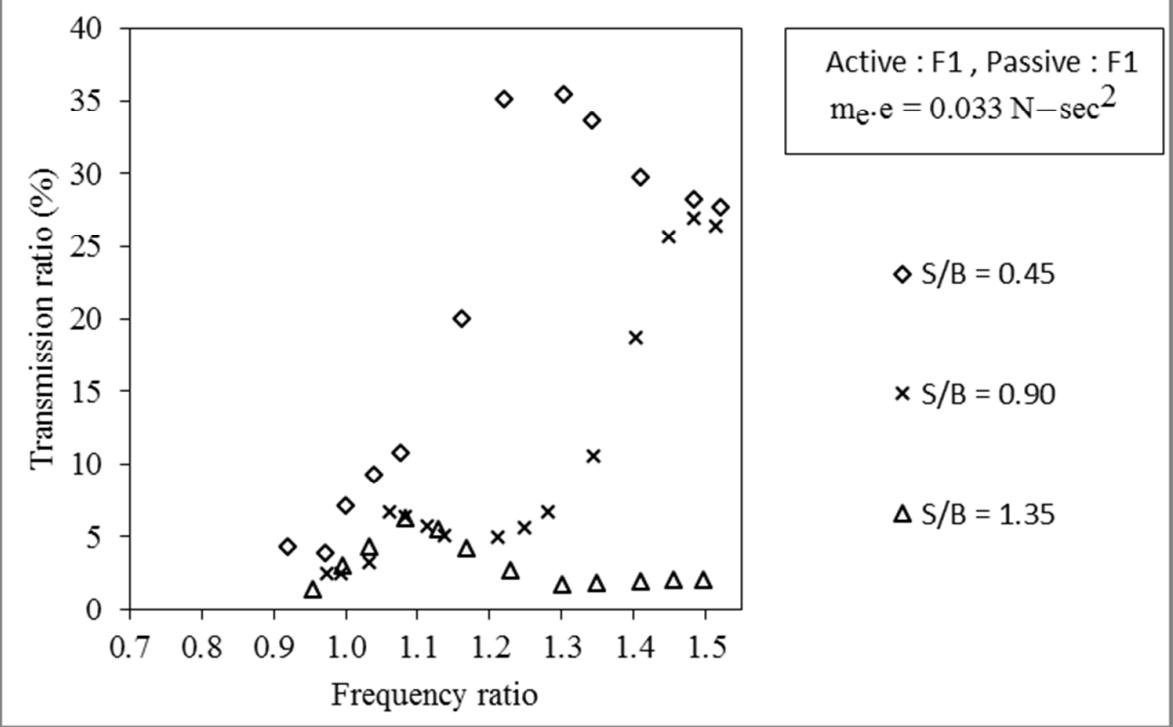

(c) For $I_{11} S_{0.45} E_{32}, I_{11} S_{0.90} E_{32}$ and $I_{11} S_{1.35} E_{32}$

Fig. 12. Variation of transmission ratio with frequency ratio due to interaction between

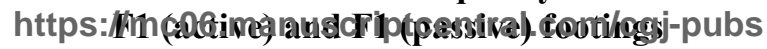




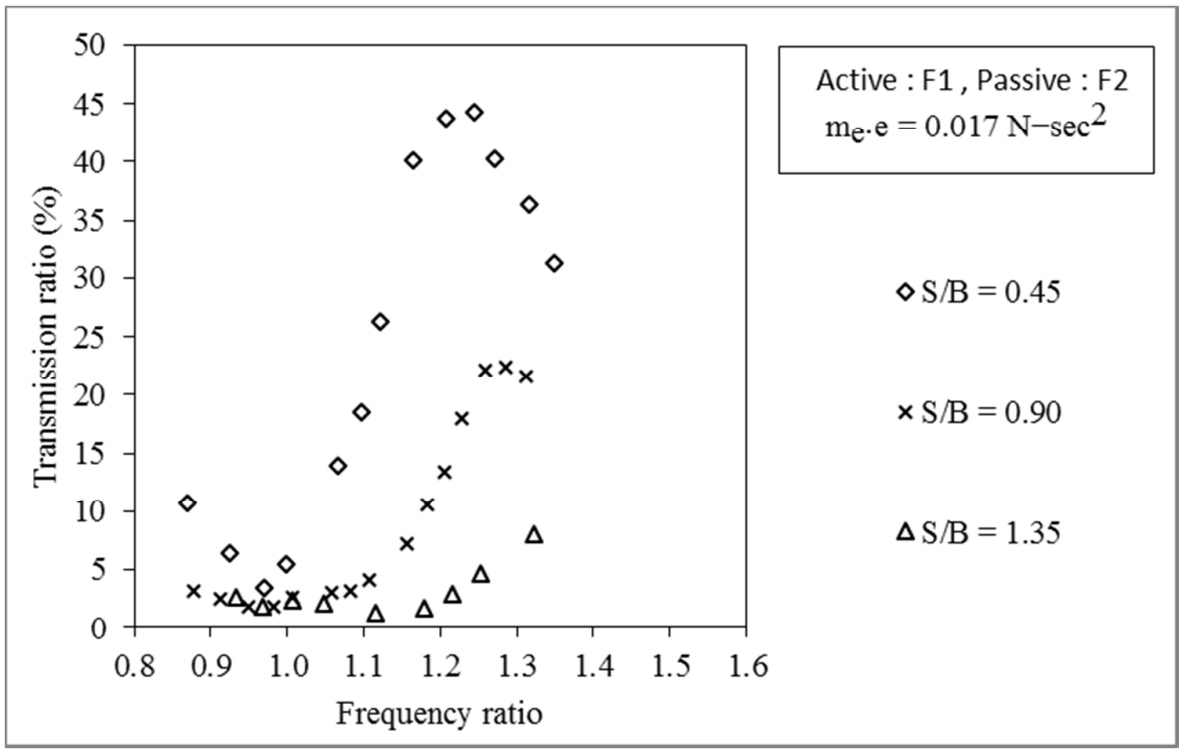

(a) For $\mathrm{I}_{12} \mathrm{~S}_{0.45} \mathrm{E}_{16}, \mathrm{I}_{12} \mathrm{~S}_{0.90} \mathrm{E}_{16}$ and $\mathrm{I}_{12} \mathrm{~S}_{1.35} \mathrm{E}_{16}$

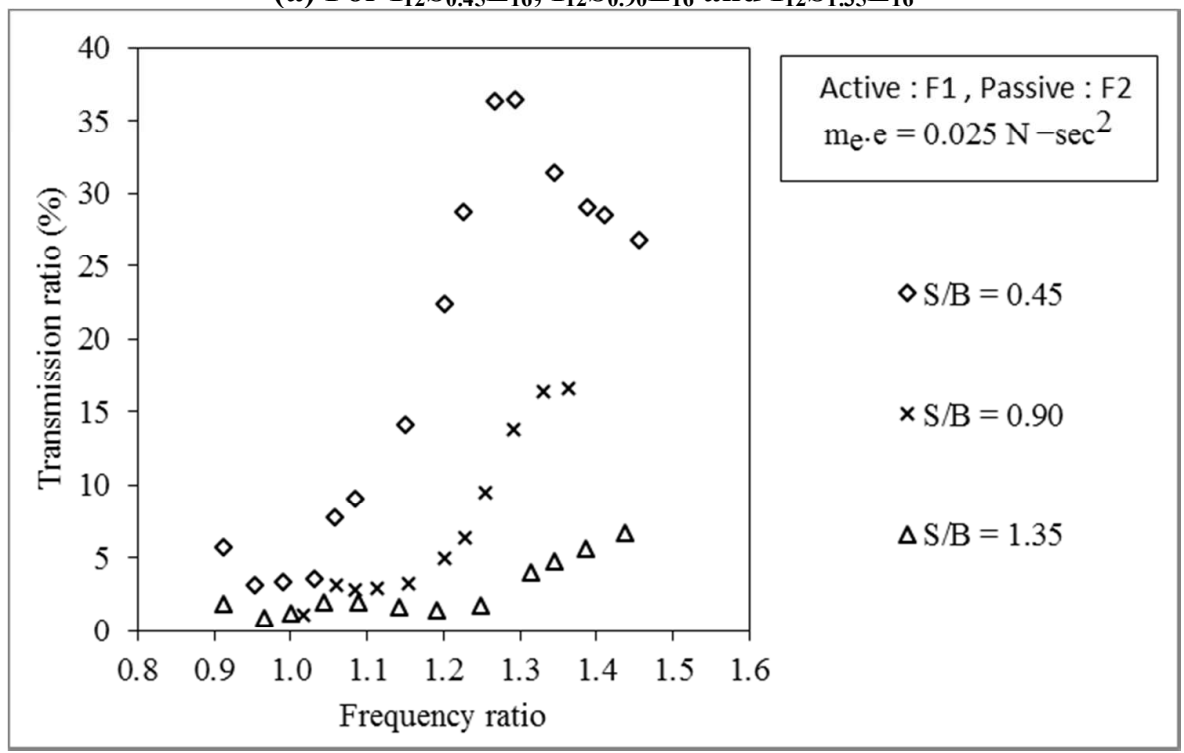

(b) For $\mathrm{I}_{12} \mathrm{~S}_{0.45} \mathrm{E}_{24}, \mathrm{I}_{12} \mathrm{~S}_{0.90} \mathrm{E}_{24}$ and $\mathrm{I}_{12} \mathrm{~S}_{1.35} \mathrm{E}_{24}$

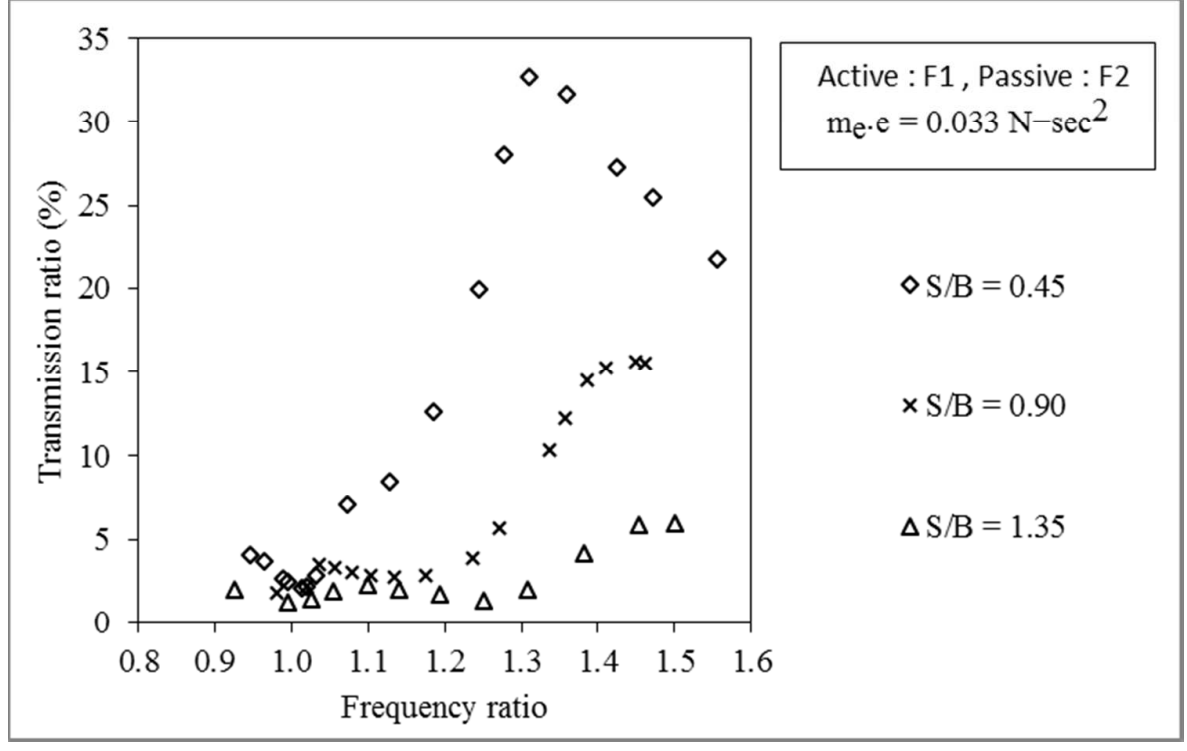

(c) For $\mathrm{I}_{12} \mathrm{~S}_{\mathbf{0 . 4 5}} \mathrm{E}_{32}, \mathrm{I}_{12} \mathrm{~S}_{0.90} \mathrm{E}_{32}$ and $\mathrm{I}_{12} \mathrm{~S}_{1.35} \mathrm{E}_{32}$

Fig. 13. Variation of transmission ratio with frequency ratio due to interaction between

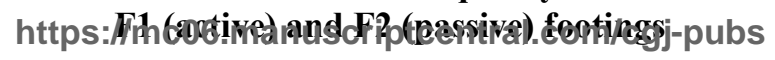




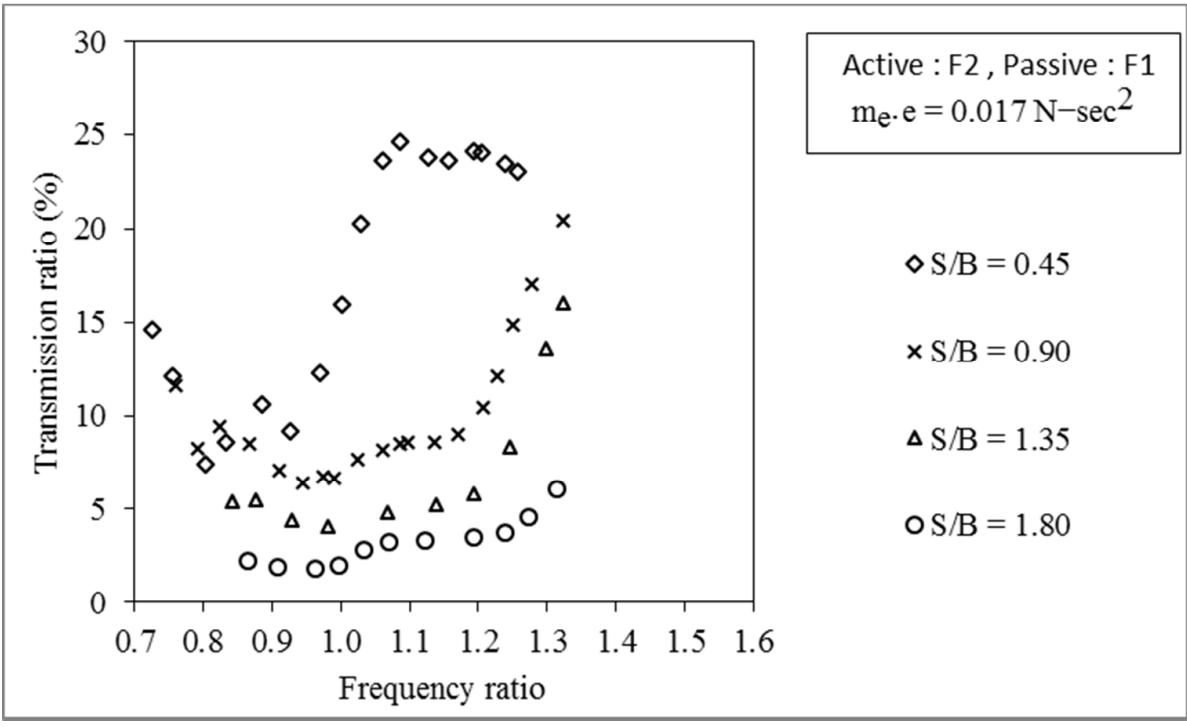

(a) For $I_{21} S_{0.45} E_{16}, I_{21} S_{0.90} E_{16}, I_{21} S_{1.35} E_{16}$ and $I_{21} S_{1.80} E_{16}$

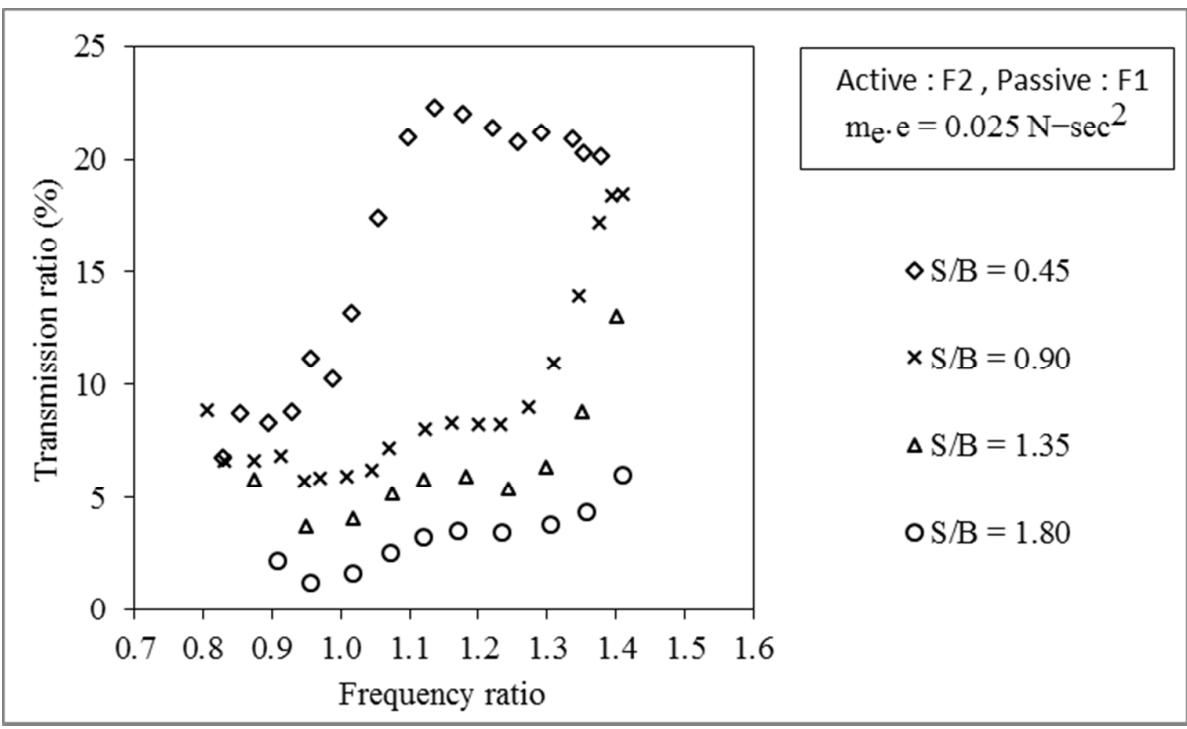

(b) For $I_{21} S_{0.45} E_{24}, I_{21} S_{0.90} E_{24}, I_{21} S_{1.35} E_{24}$ and $I_{21} S_{1.80} E_{24}$

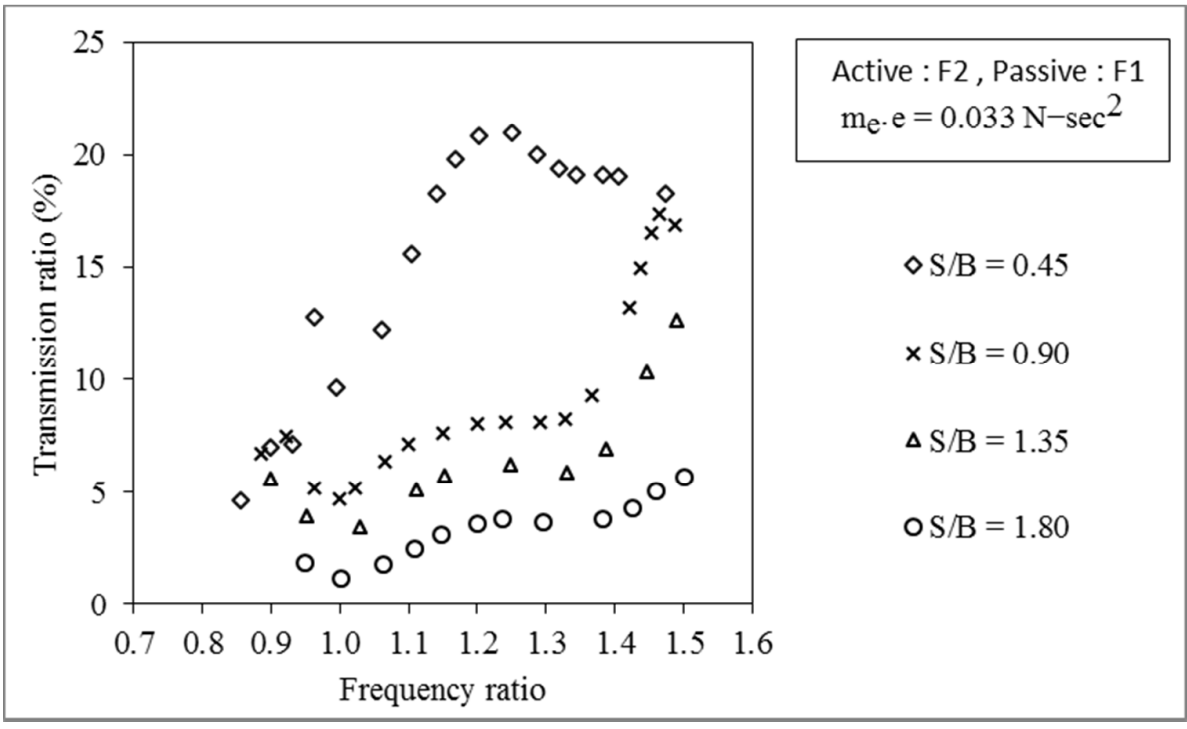

(c) For $I_{21} S_{0.45} E_{32}, I_{21} S_{0.90} E_{32}, I_{21} S_{1.35} E_{32}$ and $I_{21} S_{1.80} E_{32}$

Fig. 14. Variation of transmission ratio with frequency ratio due to interaction between

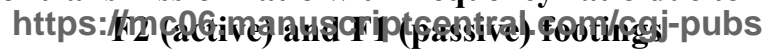




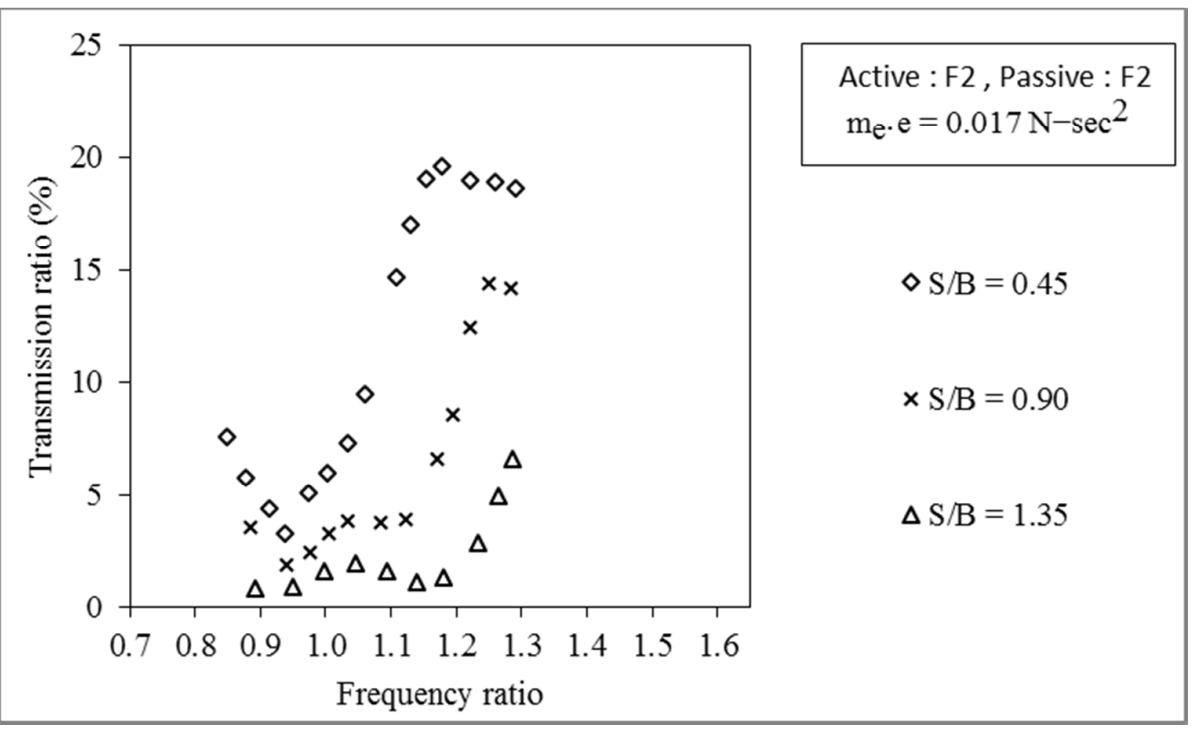

(a) For $I_{22} S_{0.45} E_{16}, I_{22} S_{0.90} E_{16}$ and $I_{22} S_{1.35} E_{16}$

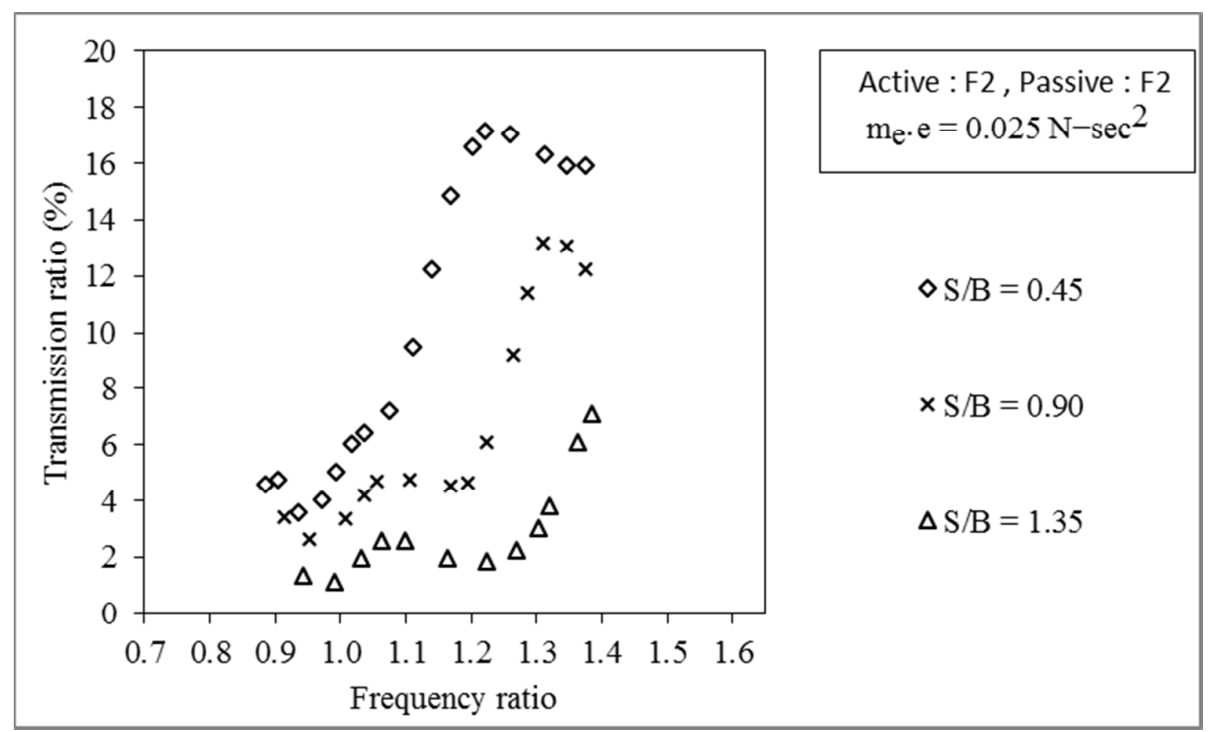

(b) For $\mathrm{I}_{22} \mathrm{~S}_{\mathbf{0 . 4 5}} \mathrm{E}_{24}, \mathrm{I}_{22} \mathrm{~S}_{\mathbf{0 . 9 0}} \mathrm{E}_{24}$ and $\mathrm{I}_{22} \mathrm{~S}_{1.35} \mathrm{E}_{24}$

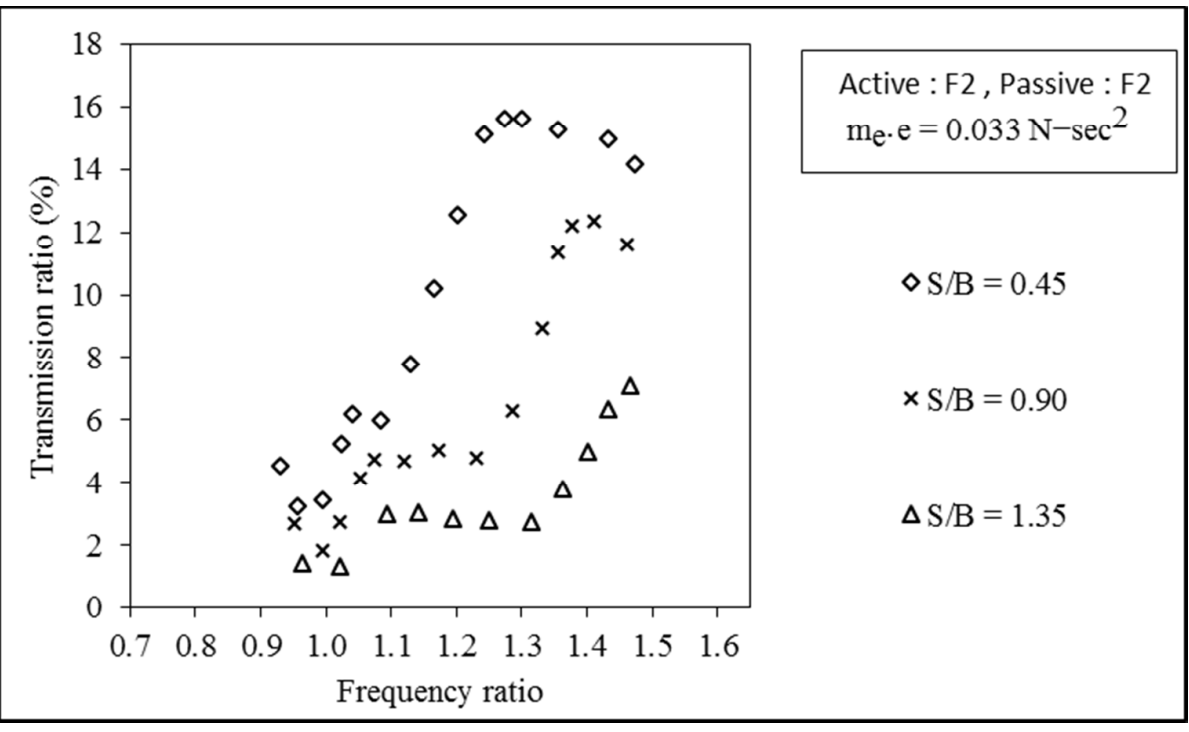

(c) For $\mathrm{I}_{22} \mathrm{~S}_{0.45} E_{32}, \mathrm{I}_{22} \mathrm{~S}_{0.90} E_{32}$ and $\mathrm{I}_{22} \mathrm{~S}_{1.35} E_{32}$

Fig. 15. Variation of transmission ratio with frequency ratio due to interaction between F2 (active) and F2 (passive) footings https://mc06.manuscriptcentral.com/cgj-pubs 
Table 1

Details of experimental program

\begin{tabular}{|c|c|c|c|c|}
\hline \multirow{2}{*}{ Spacing (S/B) } & \multicolumn{2}{|c|}{$\begin{array}{l}\text { Eccentric angle settings }(\theta) \text { : } \\
116^{\circ}, 24^{\circ} \text { and } 32^{\circ}\end{array}$} & \multirow{2}{*}{ Number of tests } & \multirow{2}{*}{ Remarks } \\
\hline & Active footing & Passive footing & & \\
\hline \multirow[t]{2}{*}{ Isolated } & F1 & Not applicable & 3 & PIT - P1 \\
\hline & $\mathrm{F} 2$ & Not applicable & 3 & PIT - P2 \\
\hline \multirow[t]{2}{*}{0.45} & $\mathrm{~F} 1$ & $\mathrm{~F} 1$ & 3 & \\
\hline & $\mathrm{F} 1$ & $\mathrm{~F} 2$ & 3 & \\
\hline \multirow[t]{2}{*}{0.90} & $\mathrm{~F} 1$ & $\mathrm{~F} 1$ & 3 & PIT - P1 \\
\hline & $\mathrm{F} 1$ & $\mathrm{~F} 2$ & 3 & \\
\hline \multirow[t]{2}{*}{1.35} & $\mathrm{~F} 1$ & $\mathrm{~F} 1$ & 3 & \\
\hline & $\mathrm{F} 1$ & $\mathrm{~F} 2$ & 3 & \\
\hline \multirow[t]{2}{*}{0.45} & $\mathrm{~F} 2$ & $\mathrm{~F} 1$ & 3 & PIT - P2 \\
\hline & $\mathrm{F} 2$ & $\mathrm{~F} 2$ & 3 & \\
\hline \multirow[t]{2}{*}{0.90} & $\mathrm{~F} 2$ & $\mathrm{~F} 1$ & 3 & \\
\hline & $\mathrm{F} 2$ & $\mathrm{~F} 2$ & 3 & \\
\hline \multirow[t]{2}{*}{1.35} & $\mathrm{~F} 2$ & $\mathrm{~F} 1$ & 3 & \\
\hline & $\mathrm{F} 2$ & $\mathrm{~F} 2$ & 3 & \\
\hline 1.80 & $\mathrm{~F} 2$ & $\mathrm{~F} 1$ & 3 & \\
\hline
\end{tabular}


Table 2.

Dynamic properties of soil under different vibrating conditions

\begin{tabular}{|c|c|c|c|c|c|}
\hline Footing Type & Eccentric setting $(\theta)$ & $\begin{array}{l}\text { Resonant frequency, } \\
\mathrm{f}_{\mathrm{mr}}(\mathrm{rpm})\end{array}$ & $\begin{array}{l}\text { Natural frequency of } \\
\quad \text { soil, } f_{n}(r p m)\end{array}$ & Damping ratio (\%) & Soil stiffness, k (MN/m) \\
\hline \multirow[t]{3}{*}{ F1 } & $16^{\circ}$ & 2233 & 2156 & 18.39 & 16.92 \\
\hline & $24^{\circ}$ & 2081 & 2011 & 18.23 & 14.72 \\
\hline & $32^{\circ}$ & 1976 & 1909 & 18.28 & 13.26 \\
\hline \multirow[t]{3}{*}{$\mathrm{F} 2$} & $16^{\circ}$ & 2306 & 2262 & 13.78 & 25.98 \\
\hline & $24^{\circ}$ & 2177 & 2124 & 15.46 & 22.91 \\
\hline & $32^{\circ}$ & 2052 & 1998 & 16.17 & 20.27 \\
\hline
\end{tabular}


Table 3.

Comparison of present results with Bhoumik (1989)

\begin{tabular}{lccr}
\hline Parameters & Bhoumik (1989) & \multicolumn{2}{c}{ Present Study } \\
\hline Footing: concrete block & $1 \mathrm{~m}$ x $0.75 \mathrm{~m} \mathrm{x} 0.7 \mathrm{~m}$ & F1: 0.55m x 0.55m x 0.20m & F2: 0.65m x 0.65m x 0.20m \\
\cline { 2 - 3 } Total vibrating mass & $1223.0 \mathrm{~kg}$ & $331.5 \mathrm{~kg}$ & $463.0 \mathrm{~kg}$ \\
Soil type (IIT Kanpur campus) & Silty clay & Clayey silt & Clayey silt \\
Eccentric setting $\left(\mathrm{N}-\mathrm{sec}^{2}\right)$ & 0.045 & $0.017-0.033$ & $0.017-0.033$ \\
\hline Test results: & & & $0.127 \mathrm{~mm}-0.222 \mathrm{~mm}$ \\
\hline Resonant displacement amplitude & $0.127 \mathrm{~mm}$ & $0.137 \mathrm{~mm}-0.275 \mathrm{~mm}$ & $2306-2052$ \\
Resonant frequency (rpm) & 2459 & $2233-1976$ & $2262-1998$ \\
Natural frequency of soil (rpm) & 2404 & $2156-1909$ & $13.78 \%-16.17 \%$ \\
Damping ratio $\left(\mathrm{D}_{\mathrm{r}}\right)$ & $14.47 \%$ & $18.30 \%$ (avg.) & \\
\hline
\end{tabular}


Table 4.

Maximum transmission ratios

\begin{tabular}{|c|c|c|c|c|c|c|c|}
\hline \multirow{3}{*}{$\begin{array}{c}\text { Footing } \\
\text { Active } \downarrow\end{array}$} & \multirow{3}{*}{$\begin{array}{c}\text { Passive } \rightarrow \\
\theta \rightarrow \\
(\mathrm{S} / \mathrm{B}) \downarrow\end{array}$} & \multicolumn{3}{|c|}{$\mathrm{F} 1$} & \multicolumn{3}{|c|}{$\mathrm{F} 2$} \\
\hline & & $16^{\circ}$ & $24^{\circ}$ & $32^{\circ}$ & $16^{\circ}$ & $24^{\circ}$ & $32^{\circ}$ \\
\hline & & \multicolumn{6}{|c|}{ Maximum transmission ratio (\%) } \\
\hline \multirow{2}{*}{$\mathrm{F} 1$} & 0.90 & 29.16 & 28.69 & 26.91 & 22.46 & 16.56 & 15.63 \\
\hline & 1.35 & 3.02 & 2.35 & 2.00 & 8.00 & 6.64 & 5.90 \\
\hline \multirow[t]{4}{*}{$\mathrm{F} 2$} & 0.45 & 25.07 & 22.27 & 20.96 & 19.59 & 17.18 & 15.63 \\
\hline & 0.90 & 20.48 & 18.44 & 17.38 & 14.43 & 13.21 & 12.36 \\
\hline & 1.35 & 16.05 & 13.07 & 12.65 & 6.58 & 7.12 & 7.10 \\
\hline & 1.80 & 6.10 & 5.90 & 5.70 & Negligible & Negligible & Negligible \\
\hline
\end{tabular}

